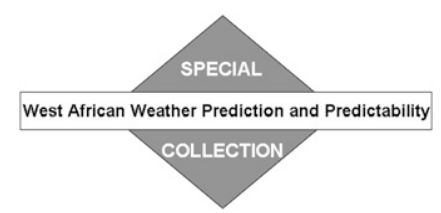

\title{
An Intercomparison of Simulated Rainfall and Evapotranspiration Associated with a Mesoscale Convective System over West Africa
}

\author{
Françoise Guichard, ${ }^{\mathrm{a}}$ Nicole Asencio, ${ }^{\mathrm{a}}$ Christophe Peugeot, ${ }^{\mathrm{b}}$ Olivier Bock, ${ }^{\mathrm{c}}$ \\ JEAN-LuC REDELSPERGER, ${ }^{a}$ XUEFENG CUi, ${ }^{d}$ MATTHEW GARVERT,,${ }^{\mathrm{e}}$ BENJAMIN LAMPTEY, ${ }^{\mathrm{f}}$ \\ EMILIANO Orlandi, ${ }^{\mathrm{g}}$ JUlia SANDER, ${ }^{\text {h }}$ Federico Fierli, ${ }^{\mathrm{i}}$ Miguel Angel GaERTner, ${ }^{\mathrm{e}}$

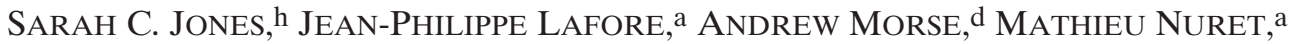

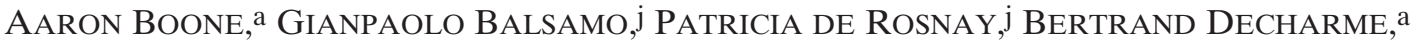 \\ PHILIP P. HARRIS, ${ }^{\mathrm{k}}$ AND J.-C. BERGÈs ${ }^{1}$ \\ ${ }^{a}$ CNRM, CNRS, and Météo-France, Toulouse, France \\ $b$ Hydrosciences, IRD, Montpellier, France \\ ${ }^{c}$ LAREG/IGN, Marne-la-Vallée, France, and Service d'Aéronomie, CNRS and Université Paris, Paris, France \\ $d$ University of Liverpool, Liverpool, United Kingdom \\ e Universidad de Castilla-La Mancha, Toledo, Spain

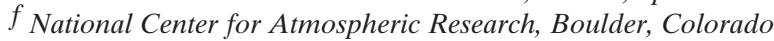 \\ $g$ University of Ferrara, Department of Physics, Ferrara, Italy, and Institute of Atmospheric Science and \\ Climate, CNR, Bologna, Italy

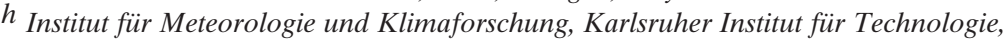 \\ Karlsruhe, Germany \\ ${ }^{i}$ Institute of Atmospheric Science and Climate, CNR, Bologna, Italy \\ $j$ ECMWF, Reading, United Kingdom \\ ${ }^{k}$ CEH, Wallingford, United Kingdom \\ $l_{\text {PRODIG, Université Paris 1, Paris, France }}$
}

(Manuscript received 16 December 2008, in final form 7 September 2009)

\begin{abstract}
An evaluation of precipitation and evapotranspiration simulated by mesoscale models is carried out within the African Monsoon Multidisciplinary Analysis (AMMA) program. Six models performed simulations of a mesoscale convective system (MCS) observed to cross part of West Africa in August 2005.

Initial and boundary conditions are found to significantly control the locations of rainfall at synoptic scales as simulated with either mesoscale or global models. When initialized and forced at their boundaries by the same analysis, all models forecast a westward-moving rainfall structure, as observed by satellite products. However, rainfall is also forecast at other locations where none was observed, and the nighttime northward propagation of rainfall is not well reproduced. There is a wide spread in the rainfall rates across simulations, but also among satellite products.

The range of simulated meridional fluctuations of evapotranspiration $(E)$ appears reasonable, but $E$ displays an overly strong zonal symmetry. Offline land surface modeling and surface energy budget considerations show that errors in the simulated $E$ are not simply related to errors in the surface evaporative fraction, and involve the significant impact of cloud cover on the incoming surface shortwave flux.

The use of higher horizontal resolution (a few $\mathrm{km}$ ) enhances the variability of precipitation, evapotranspiration, and precipitable water (PW) at the mesoscale. It also leads to a weakening of the daytime precipitation, less evapotranspiration, and smaller PW amounts. The simulated MCS propagates farther northward and somewhat faster within an overall drier atmosphere. These changes are associated with a strengthening of the links between PW and precipitation.
\end{abstract}

Corresponding author address: Françoise Guichard, CNRM, CNRS/ Météo-France, 42 Ave. Coriolis, 31057 Toulouse CEDEX, France.

E-mail: francoise.guichard@meteo.fr

\section{Introduction}

At the present time, large-scale model simulations of rainfall over West Africa suffer from major weaknesses, in both numerical weather prediction (NWP) systems 
(Agustí-Panareda et al. 2009) and climate general circulation models (Hourdin et al. 2010). In particular, mesoscale convective systems (MCSs) are still poorly handled by large-scale models (e.g. Lebel et al. 2000). This is of concern because MCSs are major contributors to the rainfall amounts over West Africa (Mathon et al. 2002), where they lead to local flooding every year. Conversely, droughts are largely explained by a reduction in the number of MCSs in a season (Le Barbé et al. 2002). Also specific to West Africa is the difficulty encountered by large-scale models in reproducing the strong climatological gradient of rainfall observed in the Sahel, on the order of $1 \mathrm{~mm} \mathrm{~km}^{-1}$ (Le Barbé and Lebel 1997).

Even beyond the representation of MCSs, a proper simulation of rainfall and surface evapotranspiration, together with atmospheric water transport, is required for an accurate estimation of water budgets (e.g.; Drusch and Viterbo 2007). Such estimates, therefore, require the modeling of atmospheric processes and land-oceanatmosphere interactions over a range of temporal and spatial scales. For example, the diurnal cycle of solar radiation over West Africa is responsible for very significant diurnal modulations of atmospheric convection, whether dry, moist, shallow, or deep precipitating (Mohr 2004; Laing et al. 2008). This modulation highlights the important role of interactions between surface and atmospheric processes at this time scale. Similarly, a single MCS, with a spatial scale ranging from tens to hundreds of kilometers, interacts with larger scales through its motion across several hundred kilometers over West Africa.

Global forecast models have a typical gridbox width of several tens of kilometers and, consequently, are able to partly resolve only the largest MCSs. As a result, most MCS processes are represented in these large-scale models by subgrid parameterizations. Our current understanding of these processes is limited and this affects the formulation and basic concepts underlying their parameterizations. For instance, the major impact of cold pools on MCS life cycles, via their influences on further convective triggering and MCS propagation, is well recognized (Houze and Betts 1981; Corfidi 2003).
However, a comprehensive formulation of cold pools is still to be introduced into parameterizations (Bukovsky et al. 2006). In fact, the impacts of these crude representations of processes on the simulated water budget are not well known. They are likely to vary among largescale models, which each implements a different set of subgrid parameterizations.

More recently, advances in computing resources have allowed mesoscale modeling to become an effective and practical tool for studying MCSs over West Africa (Diongue et al. 2002), as well as the West African monsoon over longer time scales (Gallée et al. 2004). By "mesoscale modeling" here, we specifically mean atmospheric numerical modeling with a resolution ranging from a few to a few tens of kilometers. For grid spacing larger than a few kilometers, such models still require a parameterization of convection because deep, precipitating convective cells remain subgrid phenomena. A number of studies have pointed to a strong sensitivity of the modeled precipitation to the convective parameterization, even within such finer-resolution frameworks (e.g.; Guichard et al. 2000; Liu et al. 2001; Jankov et al. 2005; Done et al. 2006; Liu et al. 2006). The main difference is that MCSs are at least partly resolved by mesoscale models, while they are not impacted by large-scale models.

From this perspective, mesoscale models may be more appropriate than large-scale models for studying hydrology. This raises other issues though, as discussed by Davis et al. (2003) and Moncrieff and Liu (2006) for simulations over North America using horizontal resolutions of about 10 to a few 10s of kilometers. It is currently unknown how accurately mesoscale models depict water budgets over West Africa, and how they compare to each other in their simulations of individual MCSs. This study aims to document this issue using results from an intercomparison of mesoscale models conducted within the African Monsoon Multidisciplinary Analysis (AMMA) program (Redelsperger et al. 2006). The study focuses on the simulation of an observed MCS from 28 to 29 August 2005. The main objective is to evaluate and discuss some important components of the associated water budgets from the mesoscale to the synoptic scale.

\footnotetext{
FIG. 1. (a) Latitude-time diagram of PW (shaded) and 3-h cumulative rainfall (isolines, 2 and $5 \mathrm{~mm}$ ) averaged over $10^{\circ} \mathrm{W}-20^{\circ} \mathrm{E}$ for a 7-day period centered on 28 Aug 2005 , and average lontime Hovmöller diagrams of (b) rainfall (shaded) and meridional wind at $700 \mathrm{hPa}$ [contour interval (CI) of $2.5 \mathrm{~m} \mathrm{~s}^{-1}$ ], (c) wind speed (shaded) and meridional wind at $925 \mathrm{hPa}(\mathrm{CI}$ of $2.5 \mathrm{~m} \mathrm{~s}^{-1}$, note that the $0 \mathrm{~m} \mathrm{~s}^{-1}$ isocountour is dotted), (d) PW tendency (shaded) and meridional wind at $700 \mathrm{hPa}$, and (e) $\mathrm{PW}$ and rainfall (isolines). In (b)-(e) an average over $7^{\circ} \mathrm{N}-$ $16^{\circ} \mathrm{N}$ is shown. PW and wind fields are from the 6-h ECMWF analysis, and rainfall corresponds to the 3-h TRMM product. In (d), the PW tendency at time $t$ corresponds to $\mathrm{PW}(t+12 \mathrm{~h})-$ $\mathrm{PW}(t-12 \mathrm{~h})$, this filters out diurnal fluctuations that are known to be of limited accuracy in NWP analyses over Africa (Bock et al. 2007).
} 
(a) rainfall (isolines) \& precipitable water PW (shading)
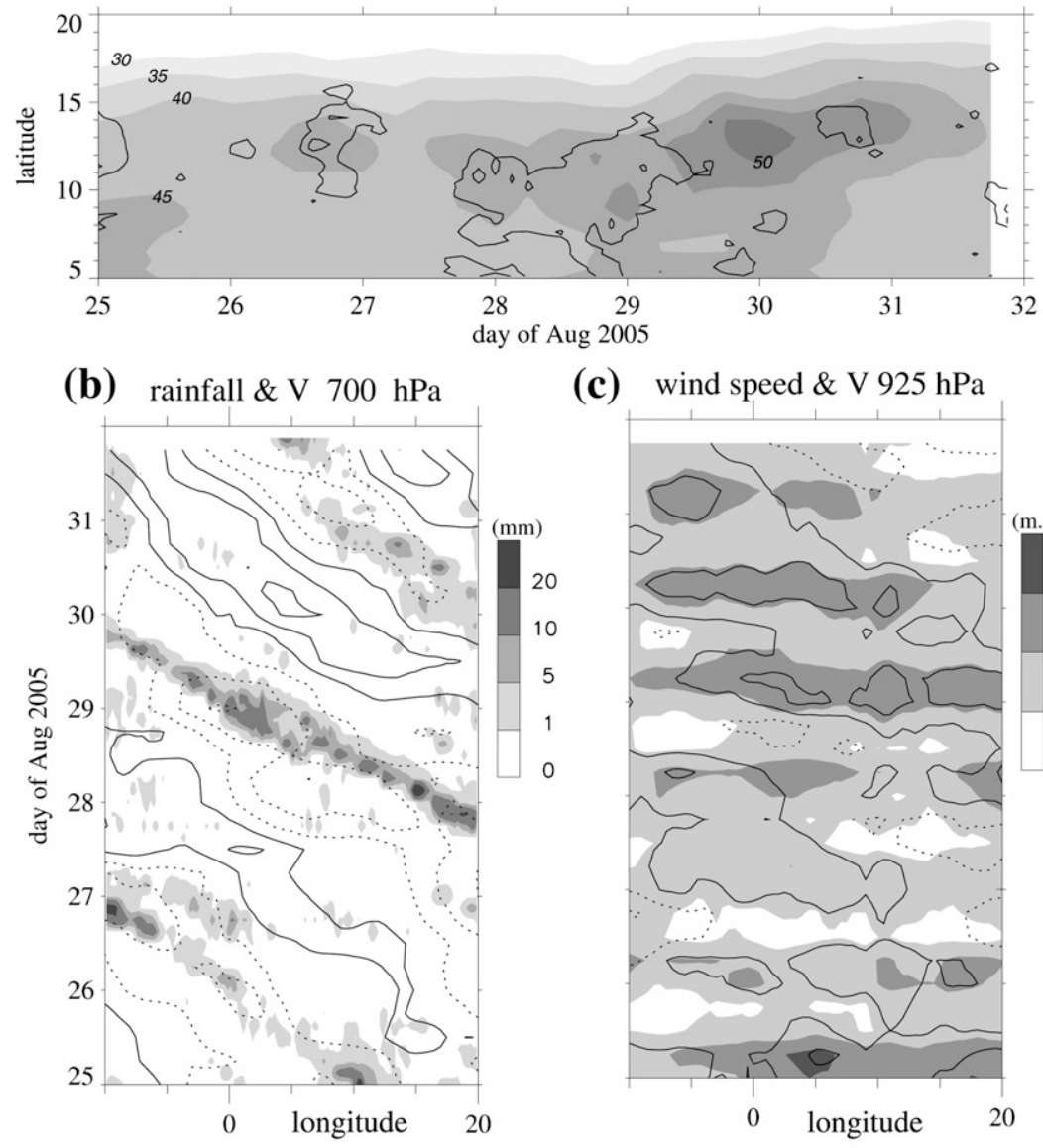

(c) wind speed \& V $925 \mathrm{hPa}$
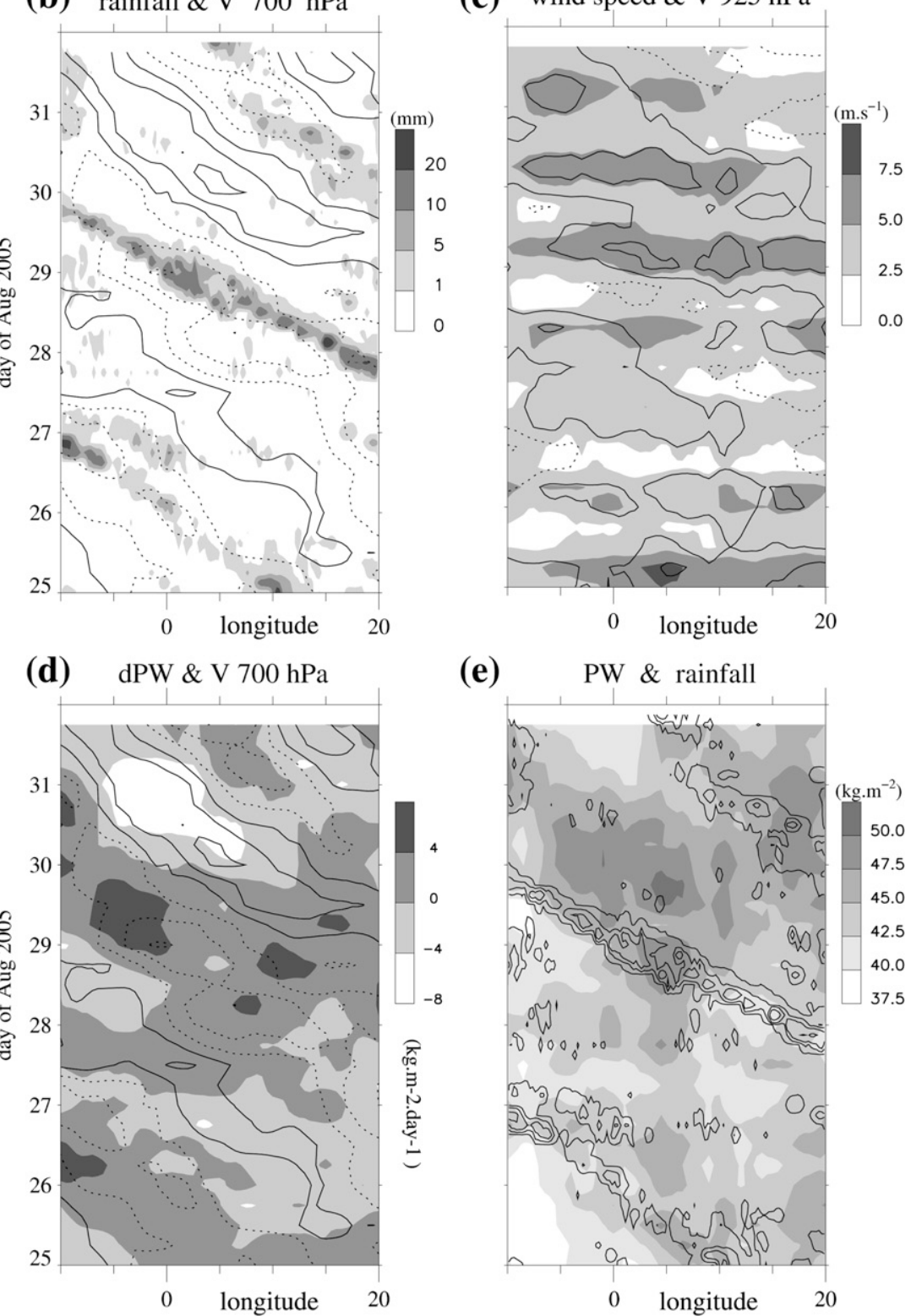

(e)

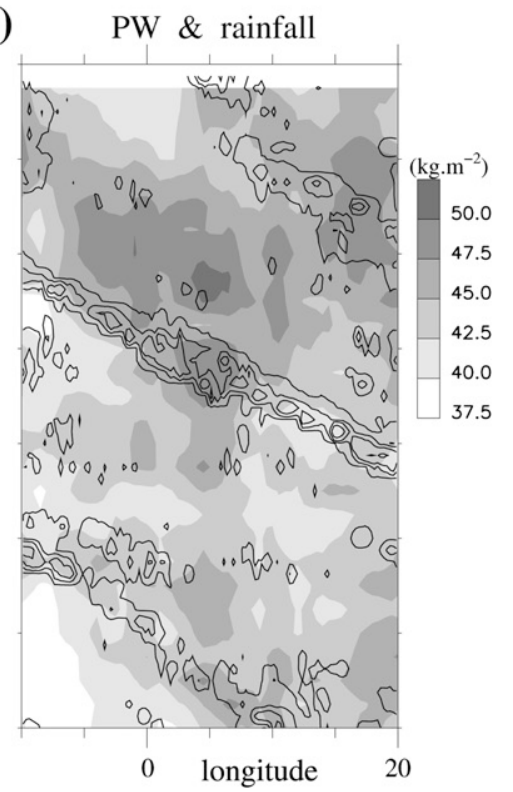



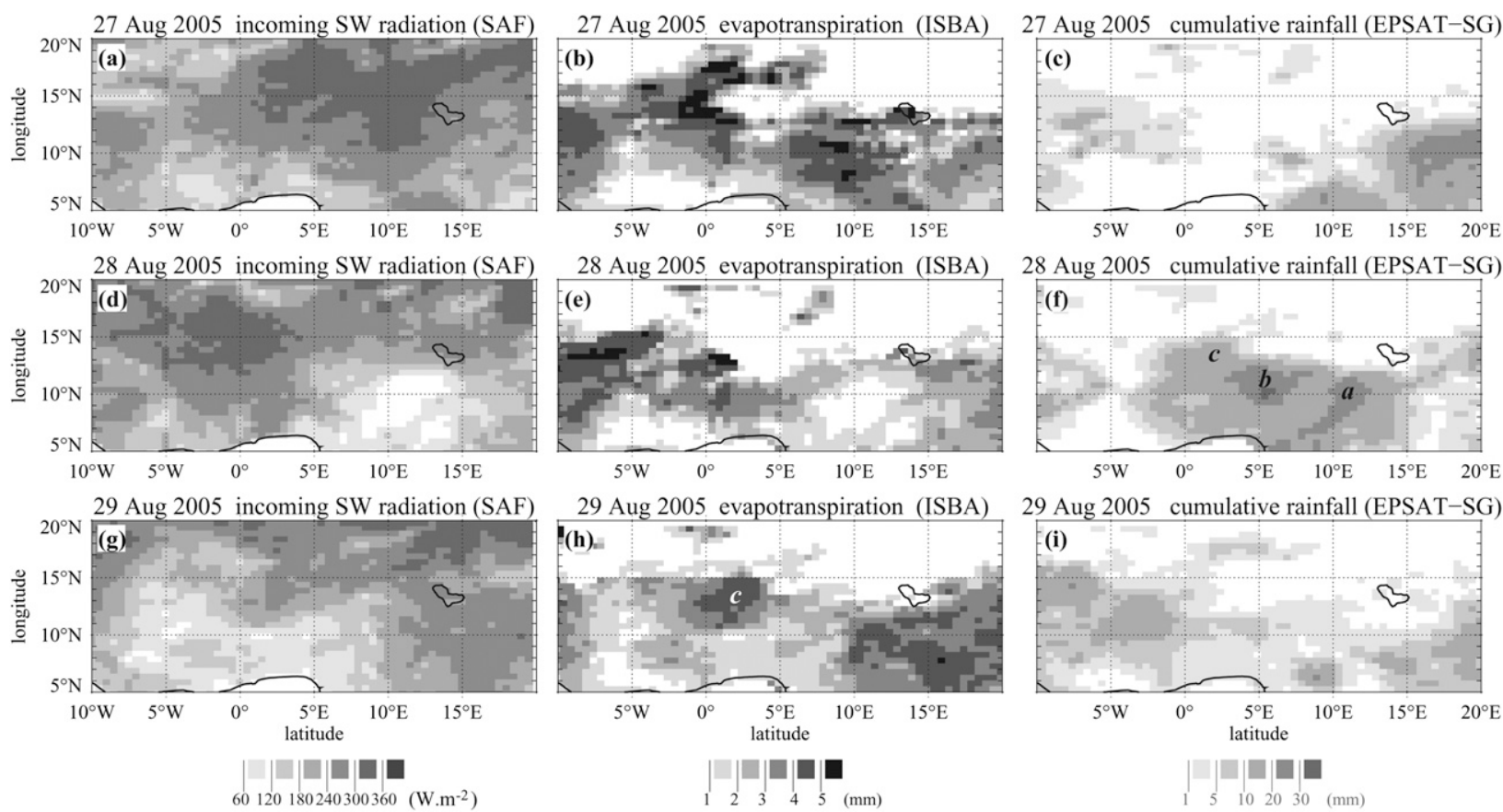

FIG. 2. Series of maps of 24-h mean (a) surface shortwave incoming flux (SAF product), (b) evapotranspiration (ISBA land surface model), and (c) cumulative precipitation (EPSAT-SG) for 27 Aug 2005. (d)-(f) and (g)-(i) As in (a)-(c), but for 28 and 29 Aug 2005 , respectively. Fields are shown on the same $0.5^{\circ} \times 0.5^{\circ}$ grid.

The models and simulations are presented in section 3. The satellite products used to characterize the MCSs and their accuracies are presented and discussed in section 4. Simulated rainfall and evapotranspiration fields are then compared and evaluated in section 5 . Additional diagnostics and further analyses are carried out in sections 6 and 7 using a set of simulations by a single mesoscale model.

\section{The case study}

Our case study focuses on 28-29 August 2005, a period during which moist convection developed and propagated over West Africa in the form of a succession of MCSs that provided rainfall across a wide area. It occurred during the period of the AMMA "2005 dryrun exercise," which involved several NWP centers. A more observationally based characterization of the 28-29 August 2005 case study can be found in Peugeot et al. (2007). At synoptic scale, this day coincides with the end of a relatively dry phase [lower amounts of precipitable water (PW) and rainfall; see Fig. 1a] and the start of a period of enhanced African westerly wave activity, as captured by time-longitude diagrams of meridional wind at $700 \mathrm{hPa}$ (Fig. 1b). According to several satellite precipitation products, this involved significant coupling with moist convection (Fig. 1b), which is seen as a coherent band of rainfall that develops from east to west in the $700-\mathrm{hPa}$ easterlies [such a scenario is reported in several previous studies; e.g., Redelsperger et al. (2002)]. This synoptic structure was possibly helpful in providing some large-scale control to the simulations of rainfall, as suggested by Söhne et al. (2008); furthermore, this would be consistent with Liu et al. (2006). In contrast, the development of daytime convection during 27 August was widespread but gave rise to fairly weak evening rainfall amounts (Fig. 1b). Nevertheless, the dynamics of the lower levels is dominated by a strong diurnal cycle over West Africa (e.g.; Parker et al. 2005; Peyrillé et al. 2007; Lothon et al. 2008), as illustrated for this period in Fig. 1c, which shows a nighttime maximum of the monsoon flow. In addition, the last days of the period are characterized by an overall enhancement of the lowlevel winds.

The links between PW, 700-hPa meridional winds, and rainfall are not very well known at this scale. Figure $1 \mathrm{~d}$ shows that $\mathrm{PW}$ increases significantly as the meridional wind is northerly at $700 \mathrm{hPa}$. This involves large PW fluctuations occurring primarily below $700 \mathrm{hPa}$, in agreement with Couvreux et al. (2010). In addition, fluctuations of PW are less tightly related to the low-level monsoon flow than when observed prior to the monsoon onset (Couvreux et al. 2010). Indeed, evapotranspiration and precipitation are expected to become more 

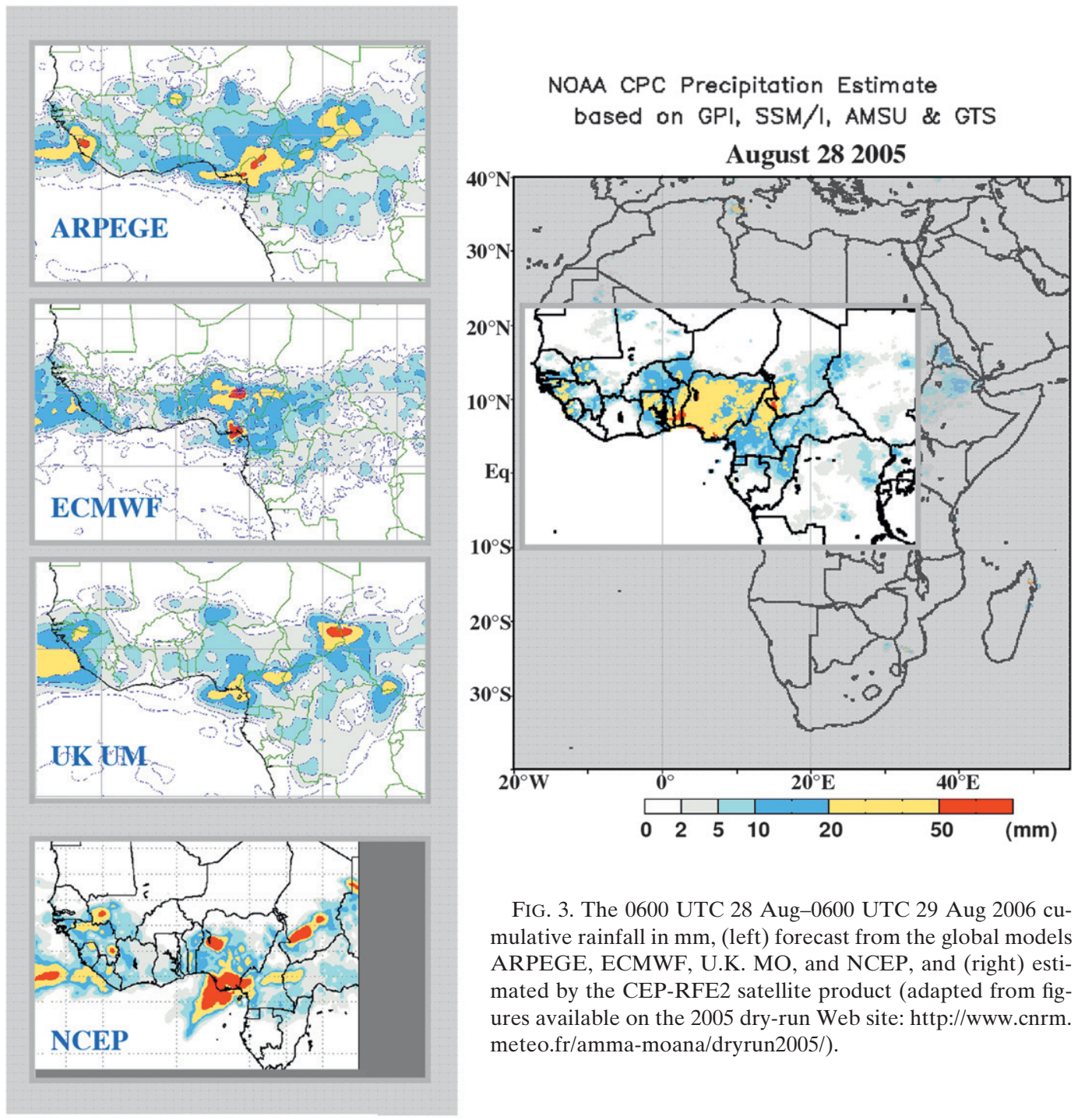

FIG. 3. The 0600 UTC 28 Aug-0600 UTC 29 Aug 2006 cumulative rainfall in $\mathrm{mm}$, (left) forecast from the global models ARPEGE, ECMWF, U.K. MO, and NCEP, and (right) estimated by the CEP-RFE2 satellite product (adapted from figures available on the 2005 dry-run Web site: http://www.cnrm. meteo.fr/amma-moana/dryrun2005/).

important drivers of PW fluctuations during the monsoon than prior to its onset, when moisture advection dominates the water budget. Here, it is the PW variability that seems to be enhanced as the synoptic activity becomes more important during and after the major 28-29 August rainfall sequence. PW remains then higher throughout the Sahel (Fig. 1a). Some maxima of PW coincide with rainfall, for instance, on 28 August around $8^{\circ} \mathrm{E}$ (Fig. 1e) and on 26 August at $13^{\circ} \mathrm{N}$ (Fig. 1a). Other local maxima occur the day after rainfall, for instance, on 29 August at $5^{\circ} \mathrm{E}$ (Fig. 1e) and at $13^{\circ} \mathrm{N}$ (Fig. 1a). Both features are in fact commonly seen during the monsoon season and are also diagnosed using analyses from other NWP models and other rainfall products (not shown).

Thus, this summary points to strong but varied links between the dynamics, rainfall, and precipitable water.
These links are, however, only marginally captured by the 6-hourly sampling of NWP analyses.

In Fig. 2, the location of the case study within the 27-29 August time interval is presented using satellitebased estimates of rainfall and surface incoming solar flux, together with the latent heat flux (LE) derived from these products with land surface modeling (Boone et al. 2009); see section 4 (and Table 3 ) for further details on these products. According to these estimates, the 24-h rainfall and evapotranspiration $(E)$ display high and related variability from one day to the next. Links between the rainfall and subsequent LE patterns are obvious but varied. For instance, the extended LE minimum centered around $8^{\circ} \mathrm{N}, 10^{\circ} \mathrm{E}$ in the lower-right sector on 28 August is related to the wide cloud cover of a complex MCS that affected the area during daytime and 
produced the rainfall patterns labeled $\boldsymbol{a}$ and $\boldsymbol{b}$ in Fig. 2f. Conversely, the westward extent of the largest $28 \mathrm{Au}$ gust rainfall pattern (label $c$ ) coincides with an overall increase in the surface latent heat flux through the next day (Fig. 2h). This local maximum is also largely shaped by the spatial structure of the surface incoming solar radiation (Fig. $2 \mathrm{~g}$ ).

Figure 3 reproduces the 24-h rainfall fields simulated by some of the global operational forecast models that participated to the 2005 dry-run exercise, together with the rainfall estimate of version 2.0 of the National Oceanic and Atmospheric Administration/Climate Prediction Center (NOAA/CPC) African rainfall estimation algorithm, referred to as CPC-RFE2, which is available from the associated Web site. The spread in location and magnitude of the rainfall is large among the forecasts. It is also representative of the differences noted each day among forecasts during the period of the dry-run exercise. The Action de Recherche à Petite et Grande Echelle (ARPEGE) model and the Unified Model (UM) are qualitatively similar to each other in terms of the locations of the rainfall maxima. They both predict an elongated southwest-northeast structure, from the Guinean coast to Lake Chad, as well as more isolated maxima (e.g., over southern Niger). A similar elongated structure is also present in the European Centre for Medium-Range Weather Forecasts (ECMWF) forecast, but it weakens significantly toward the northeast, and more rainfall is predicted over Nigeria. In this respect, the ECMWF forecast follows more closely the satellite rainfall estimate.

National Centers for Environmental Prediction (NCEP) simulation lies between the two scenarios mentioned above, but it also predicts high rainfall rates over wide areas such as the maximum centered on the Nigerian coast. The observed low rainfall amounts over Côte d'Ivoire toward $10^{\circ}-5^{\circ} \mathrm{W}$ are captured qualitatively by all simulations.

\section{Models, simulations, and outputs}

The forecasts presented above were obtained with operational global models. Simulations discussed below are performed with mesoscale models. Differences that will be found among them are to be linked to the models that are used, including their parameterizations as well as their initial and boundary conditions. One must keep in mind that a proper simulation in such a configuration is still very challenging: the observed fields result from a chain of processes differing in their nature and scales, several of which are known to be crudely treated. For instance, in the present case, the contribution of surface evapotranspiration fluxes to the atmospheric water budget is controlled by soil moisture, precipitation, and also

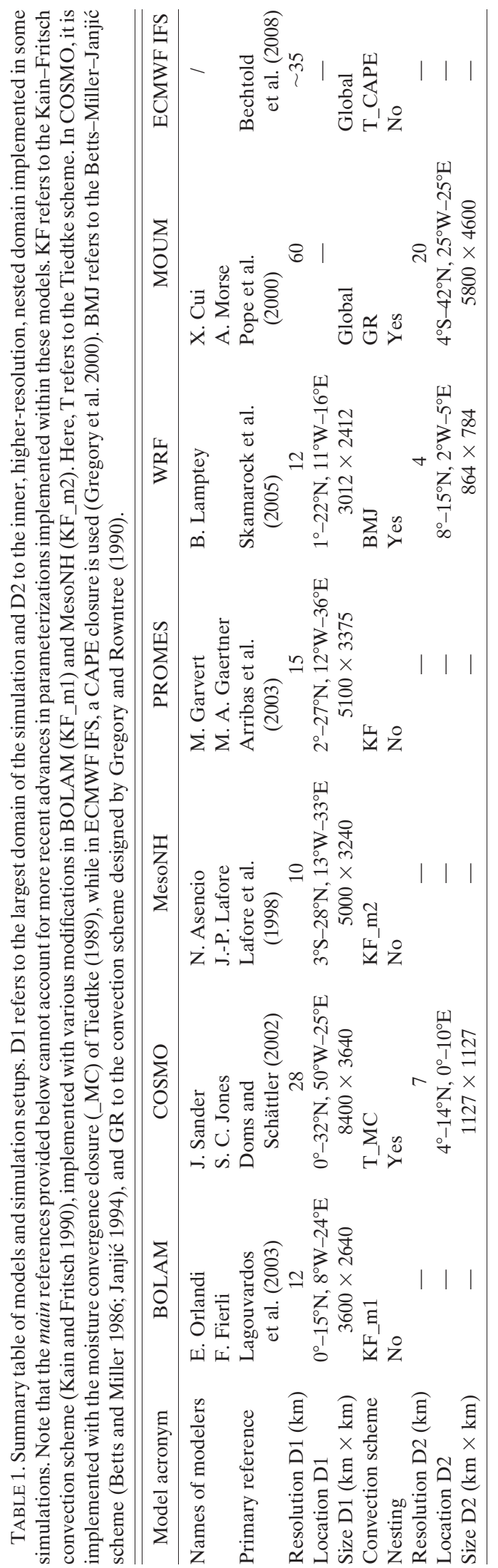


TABLE 2. Summary table of sensitivity tests performed with MesoNH. MNHEC corresponds to the simulation referred to as MesoNH in Table 1. Note that LOW_RES is the name given to the simulation MNHAT in section 7, for clarity. The analysis mentioned in the last column provides the initial and boundary conditions to the D1 domain. In HIGHRES, the inner domain D2 was maintained until 0000 UTC 29 Aug 2005, and then replaced by D'2 in order to keep the MCS at 4-km resolution as it moves westward.

\begin{tabular}{|c|c|c|c|c|c|}
\hline Simulation & $\begin{array}{c}\text { MNHEC } \\
-\end{array}$ & $\begin{array}{c}\text { MNHAT } \\
\text { LOW_RES }\end{array}$ & HIGHRES & $\begin{array}{c}\text { MNHAO } \\
-\end{array}$ & $\begin{array}{c}\text { MNHAO_2708 } \\
-\end{array}$ \\
\hline Nesting & No & No & Yes & No & No \\
\hline $\begin{array}{l}\text { Resolution } \\
\text { D2 and D'2 }(\mathrm{km})\end{array}$ & - & - & 4 & - & - \\
\hline $\begin{array}{l}\text { Location } \\
\text { D2 }\end{array}$ & - & - & $5^{\circ}-14^{\circ} \mathrm{N}, 4^{\circ}-20^{\circ} \mathrm{E}$ & - & - \\
\hline- & & & - & & \\
\hline $\mathrm{D}^{\prime} 2$ & & & $7^{\circ}-16^{\circ} \mathrm{N}, 2 \mathrm{~W}^{\circ}-14^{\circ} \mathrm{E}$ & & \\
\hline $\begin{array}{l}\text { Size D2 and D'2 } \\
\quad(\mathrm{km} \times \mathrm{km})\end{array}$ & - & - & $1728 \times 1080$ & - & - \\
\hline $\begin{array}{l}\text { Resolution } \\
\text { D1 (km) }\end{array}$ & 10 & 10 & 12 & 10 & 10 \\
\hline Start time & 0000 UTC 28 Aug & 0000 UTC 28 Aug & 0000 UTC 28 Aug & 0000 UTC 28 Aug & 0000 UTC 28 Aug \\
\hline Analysis & ECMWF & ARPEGE-Tropiques & ARPEGE-Tropiques & ARPEGE & ARPEGE \\
\hline
\end{tabular}

notably by clouds, via their impacts on the incoming shortwave radiation. It is nevertheless useful to characterize the range of variations among simulations and their departures from observational products.

Table 1 summarizes the information on the models that participated in the exercise and their configurations for this simulation. Six models simulated the case study: the Bologna Limited-Area Model (BOLAM); the Consortium for Small-Scale Modeling (COSMO) model, formerly known as the Lokal Modell); the Modèle MésoÉchelle Nonhydrostatique (MesoNH); the Pronóstico a Mesoescala (PROMES) model; the Met Office Unified Model (MOUM); and the Weather Research and Forecasting (WRF) model.

We also include below the results from the global ECMWF Integrated Forecast System (IFS) run in operational mode. This model is of interest in the present study (i) because it has a high spatial resolution of approximately $0.25^{\circ} \times 0.25^{\circ}$ in the horizontal and (ii) because it was used to generate initial and boundary conditions for the mesoscale model intercomparison presented in section 5. Note, however, that several aspects of the surface initialization varied between mesoscale models, even if based on the ECMWF surface analysis. Such widely used procedures suffer from known weaknesses with respect to the initialization of both the atmosphere and the surface. However, more advanced methods are still to be assessed. Thus, the present intercomparison is indicative of results that are to be expected from stateof-the-art methodologies.

The numerous sensitivity tests performed within this project are not discussed here. Only results from a few additional MesoNH simulations are used to discuss the sensitivities to the horizontal resolution, boundary conditions, and starting date in sections 7 and 8 (see Table 2).

These mesoscale models all include parameterizations, which vary in complexity, of surface, radiative, turbulent, convective, and cloud processes. The precise

TABLE 3. Summary table of satellite rainfall products and evapotranspiration estimates used in this study.

\begin{tabular}{|c|c|c|c|c|}
\hline \multirow[b]{2}{*}{ Acronym } & \multicolumn{3}{|c|}{ Satellite rainfall estimates } & \multirow[b]{2}{*}{$\begin{array}{l}\qquad \text { E estimates } \\
\text { ALMIP-Exp2* } \\
\text { ISBA (Noilhan and Mahfouf 1996) } \\
\text { HTESSEL (Balsamo et al. 2009) } \\
\text { JULES (Essery et al. 2003) } \\
\text { Noah (Chen and Dudhia 2001) } \\
\text { ORCHIDEE (d'Orgeval et al. 2008) }\end{array}$} \\
\hline & CPC-RFE2 & EPSAT-SG & TRMM-3B42RT & \\
\hline Reference & Love et al. (2004) & Chopin et al. (2004) & Huffman et al. (2007) & Boone et al. (2009) \\
\hline Spatial resolution $\left(^{\circ}\right)$ & 0.1 & 0.1 & 0.25 & 0.5 \\
\hline Temporal resolution & $24 \mathrm{~h}$ & $30 \mathrm{~min}$ & $3 \mathrm{~h}$ & $3 \mathrm{~h}$ \\
\hline
\end{tabular}

* ALMIP-Exp2 stands for simulations performed with land surface models used in an offline mode (unlike in the mesoscale simulations) with forcing inputs corresponding to a combination of EPSAT-SG for rainfall, LAND-SAF surface incoming radiative fluxes, and ECMWF analysis and forecast products. The names of the five LSMs considered are given in the last column together with a reference. 


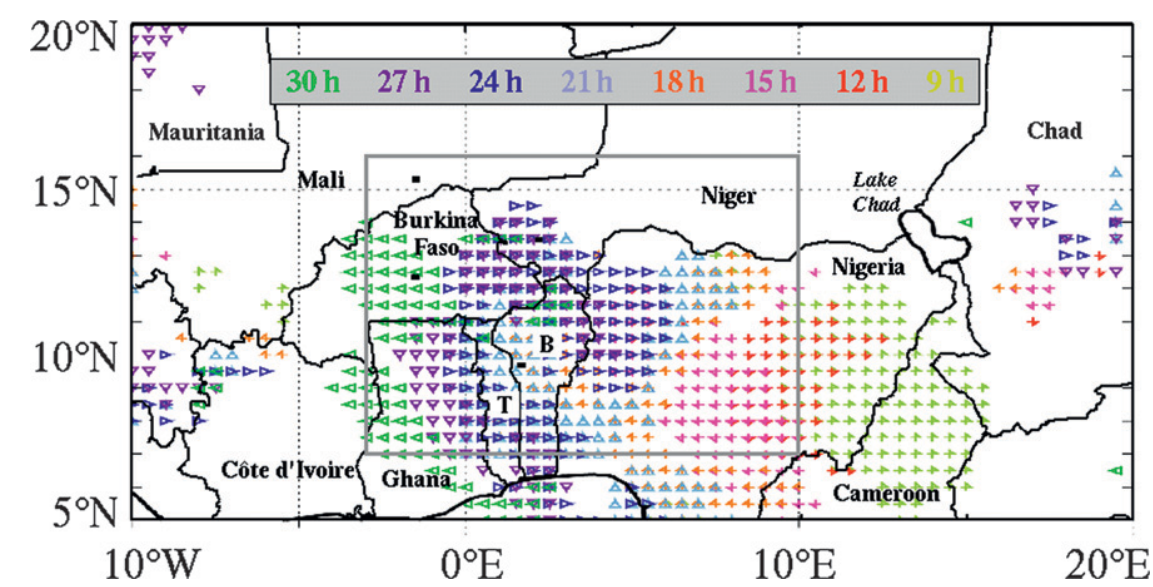

FIG. 4. A representation of rainfall propagation as inferred from satellite estimates, here for TRMM-3B42RT. For each 3-h interval, pixels where the rainfall amount is greater than half the mean value over the inner gray rectangle are marked with a symbol. Each 3 -h interval is identified by a color, corresponding to the number of hours since 0000 UTC 28 Aug, indicated in the upper gray rectangle with the same color code.

sizes of the simulated domains differ among the models, but all cover wide regional-scale areas with a resolution on the order of ten to a few tens of kilometers. Therefore, all of these models made use of convection schemes, which in this study are all of the mass flux form except for
WRF (Table 1). Some of the models incorporate a nested domain with a finer spatial resolution. In the cases of WRF (Table 1) and MesoNH (Table 2), no convection scheme is employed within their respective $4-\mathrm{km}$-grid nested domains.
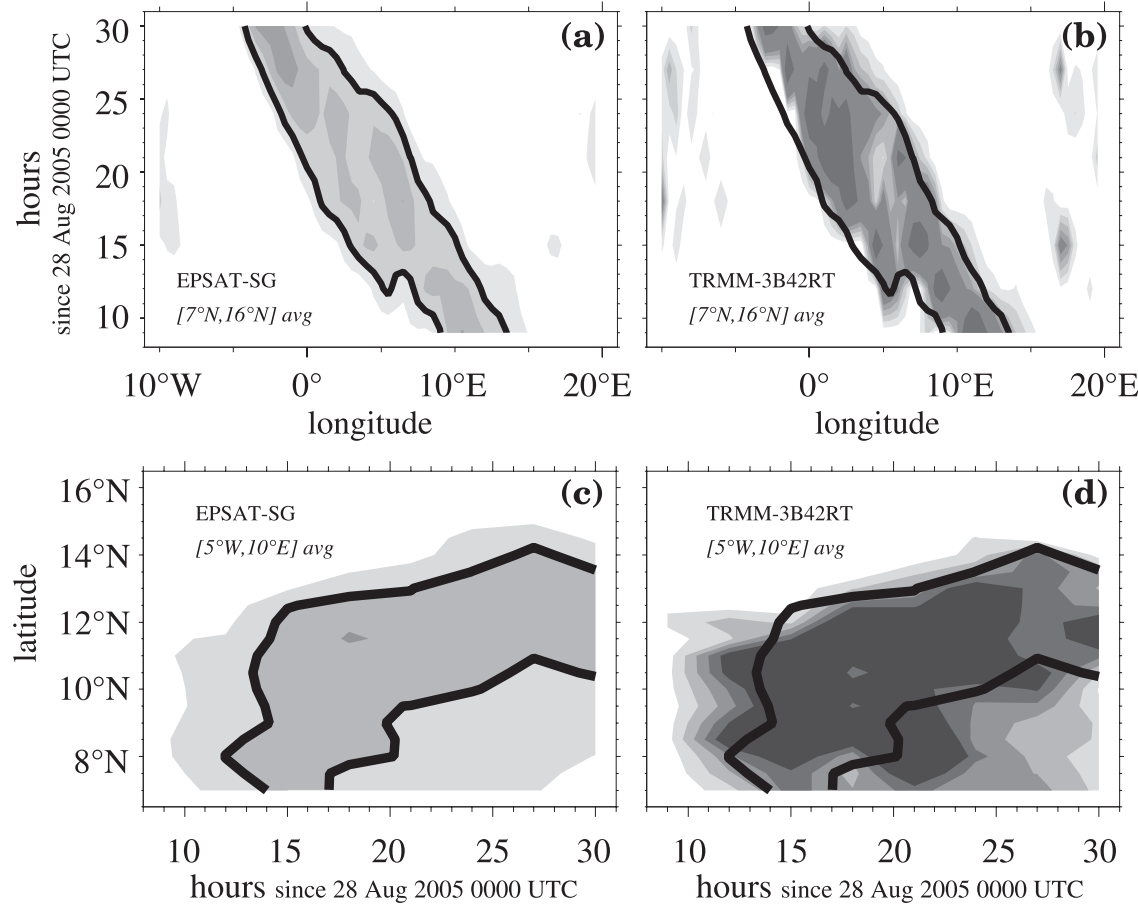

FIG. 5. (top) Longitude-time and (bottom) latitude-time diagrams of surface rainfall, averaged, respectively, over $7^{\circ}-16^{\circ} \mathrm{N}$ and $5^{\circ} \mathrm{W}-10^{\circ} \mathrm{E}$. Values above $1 \mathrm{~mm}$ are shaded, and darker as rainfall increases, from above 1, 2, 3, 4, 5, 10, 15, to $20 \mathrm{~mm}$ and above, for (left) EPSAT-SG and (right) TRMM-3B42RT. The black thick lines delineate the area where the EPSAT-SG rainfall estimate is greater than $2 \mathrm{~mm}$. The $y$ axis corresponds to the time at the end (the centered time) of the 3-h cumulative rainfall for EPSAT-SG (TRMM-3B42RT). 
This intercomparison focuses on rainfall and surface evaporation fields, both estimated from observational products and simulated by the mesoscale models. Simulated fields are considered on a 3-hourly average basis (except for MOUM, for which 3-h instantaneous values are used instead). They were provided on the native grid of each model. Where appropriate for subsequent analysis, they have been aggregated to a common latitude-longitude grid of $0.5^{\circ} \times 0.5^{\circ}$.

\section{Inferences from observational products}

\section{a. Precipitation}

Over West Africa, a weather radar network is currently being developed (Lamptey et al. 2009). Rainfall maps are derived from the dense rain gauge networks of the AMMA-Couplage de l'Atmosphère Tropicale et du Cycle Hydrologique (CATCH) sites (e.g., Peugeot et al. 2007) with a high temporal resolution only over areas of the order of $100 \mathrm{~km}$ wide. Thus, for an observationally based mapping of rainfall at larger scale, satellite-derived rainfall products constitute a commonly used alternative. Results from three existing satellite-derived rainfall products are presented below: CPC-RFE2, the Estimation des Pluies par Satellite-Seconde Génération (EPSAT-SG), and the Tropical Rainfall Measuring Mission's 3B42RT algorithm (TRMM-3B42RT) ${ }^{1}$ (Table 3 ). These products were chosen because of their relatively high space and/ or time resolutions. According to the EPSAT-SG and TRMM-3B42RT products, which both provide high temporal frequency estimates, a westward-moving rainfall structure entered the area over $7^{\circ}-16^{\circ} \mathrm{N}, 3^{\circ} \mathrm{W}-10^{\circ} \mathrm{E}$ from the east on 28 August in the afternoon and crossed its western border on 29 August in the early morning (Fig. 4). The diagnostic applied in Fig. 4 allows, to some extent, the removal of quantitative differences between the two satellite estimates. Hovmöller diagrams of the rainfall (Fig. 5, top) suggest that local maxima propagated westward somewhat faster than the envelope inferred from Fig. 4. This is consistent with satellite infrared maps, which indicate the generation of new separated deep convective elements ahead of mature convection (not shown). The envelope also propagates about $2^{\circ}$ latitude northward between the afternoon and the early morning (Fig. 5, bottom). Cumulative rainfall maps (Fig. 6) indicate a common area affected by rainfall, centered over Nigeria. The location of local extrema is fairly consistent among the three products; however, the amount of rainfall and the structure of the rainfall maps vary

\footnotetext{
${ }^{1}$ The TRMM-3B42 and TRMM-3B42RT products provide very close results in the present case.
}

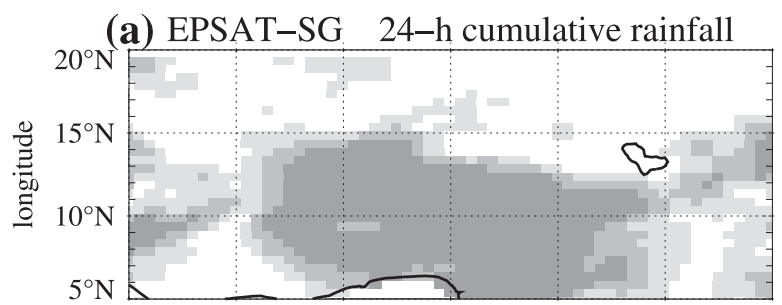

(b) CPC-RFE2 24-h cumulative rainfall

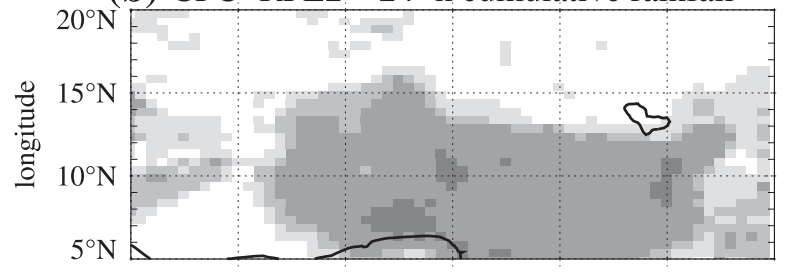

(c) TRMM-3B42RT 24-h cumulative rainfall

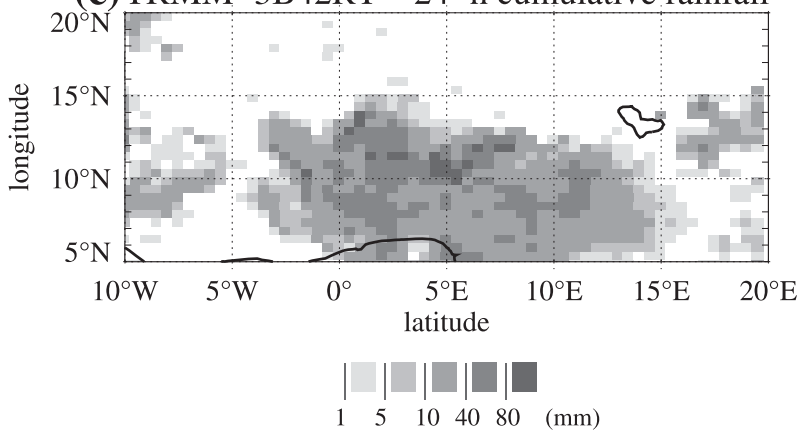

FIG. 6. The 24-h (0600 UTC 28 Aug-0600 UTC29 Aug 2005) rainfall from three satellite estimates: (a) EPSAT-SG, (b) CPCRFE2, and (c) TRMM-3B42RT. The three fields have been interpolated onto the same $0.5^{\circ} \times 5^{\circ}$ grid.

substantially. The area of precipitation in EPSAT-SG (Fig. 6a) is more extended than that in TRMM-3B42RT (Fig. 6c), but the rainfall field is smoother with much smaller rainfall maxima, and smaller rainfall amounts on average. The CPC-RFE2 estimate (Fig. 6b) lies in between EPSAT-SG and TRMM-3B42RT and, for this particular 24-h period, it also indicates a maximum of rainfall south of Lake Chad, which is not present in the two other estimates. The time of maximum rainfall varies from late evening in TRMM-3B42RT to early morning with EPSAT-SG (Fig. 5, top). This is possibly related to the distinct latitudinal gradients of rainfall provided by the two products. The similarities between the satellite precipitation products at these relatively short space and time scales indicate aspects of the MCS rainfall that should be reproduced by the models.

\section{b. Surface evapotranspiration}

In this study, we take advantage of the results from the AMMA Land Surface Model Intercomparison Project (ALMIP; Boone et al. 2009), which provides estimates of surface evapotranspiration $(E)$ as given by several 

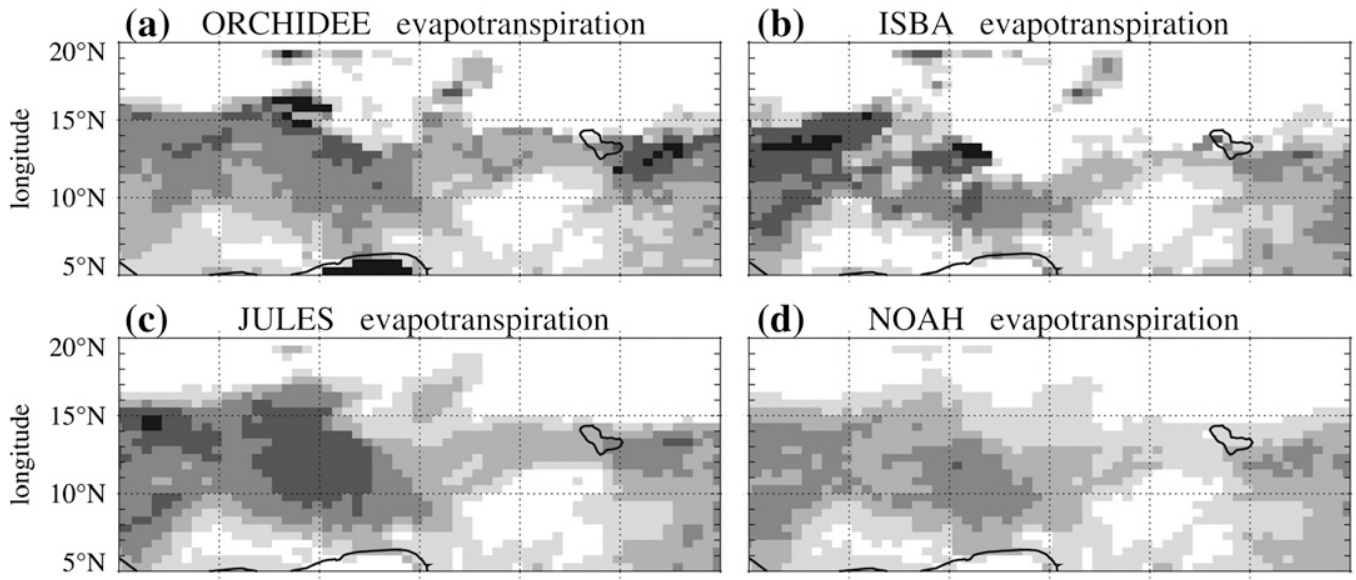

(d) NOAH evapotranspiration
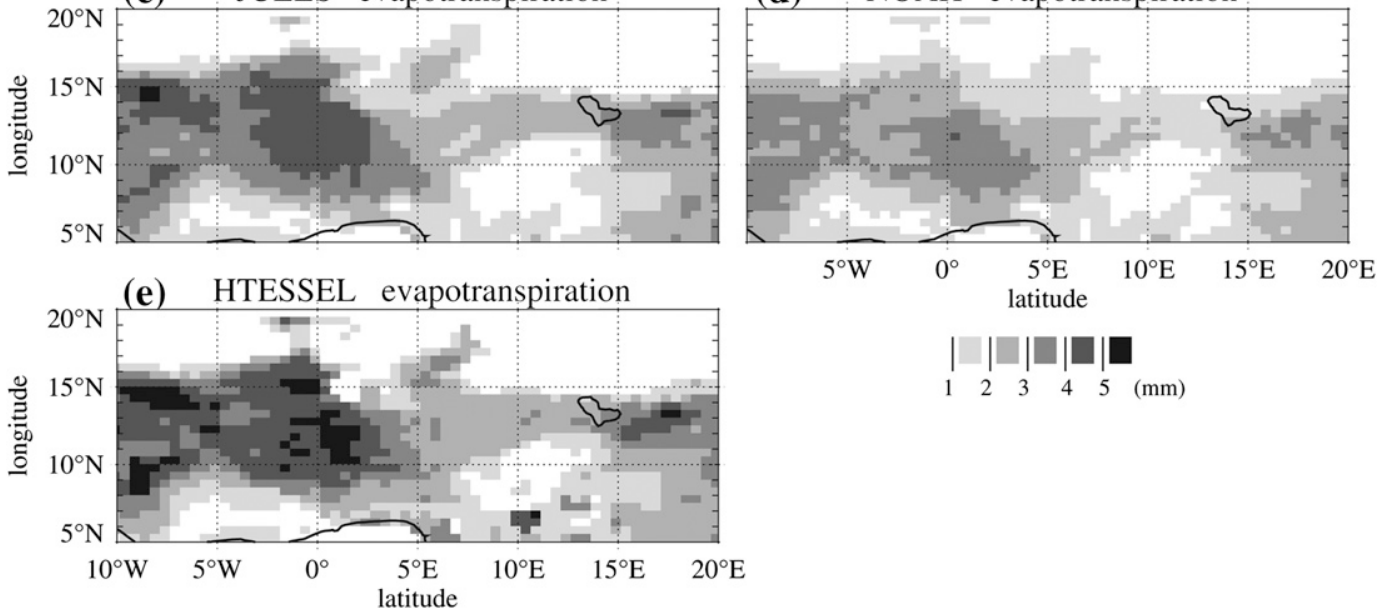

FIG. 7. The 24-h mean (0600 UTC 28 Aug-0600 UTC 29 Aug 2005) evapotranspiration rates from five offline LSM simulations, corresponding to ALMIP Exp2 runs: (a) ORCHIDEE, (b) ISBA, (c) JULES, (d) Noah, and (e) HTESSEL.

land surface models (LSMs) run in offline mode under a common atmospheric forcing based on observational products. (The data used are those from the ALMIPExp2 exercise.) The five LSMs that are currently used in the operational NWP and mesoscale models were selected from the whole ALMIP ensemble for subsequent analysis. A comparison of the $24-\mathrm{h}$ mean evapotranspiration estimates provided by these five LSMs is shown in Fig. 7. The LSMs are consistent with each other in terms of the synoptic structures discussed in section 2 and the meridional gradients. Differences among LSMs mostly concern the range of variation of $E$ values across the domain, and smaller-scale patterns. The revised land surface hydrology version of the Tiled ECMWF Scheme for Surface Exchanges over Land (HTESSEL) and the Joint U.K. Land Environment Simulator (JULES) predict the greatest $E$ values and the Noah land surface model and the Organizing Carbon and Hydrology in Dynamic Ecosystems (ORCHIDEE) land surface model predict the smallest, while the Interaction SoilBiosphere-Atmosphere (ISBA) land surface parameterization scheme lies in between. As discussed in section 2, the spatial structures of these fluxes are strongly shaped by antecedent rainfall and surface incoming solar fluxes, which lead to significant short-term departures from a zonal climatological mean.
These results provide guidance on what is to be expected in terms of agreement between LSMs seeing the same forcing, and thus they help in the interpretation of results obtained when LSMs are part of a coupled land surface-atmosphere mesoscale modeling system.

\section{Intercomparison of mesoscale models}

On at 0000 UTC 28 August, the synoptic conditions are characterized by fluctuations of thermal instability and precipitable water, which are strongly related to the wave (Fig. 8). The conditions suggest areas where the development of convection could be favored, ahead of the wave trough where both relatively high thermal instability and precipitable water are found (Doswell 1987). This is indeed where the majority of high rainfall amounts are recorded later during that day (small black squares in Fig. $8 \mathrm{~b}$ and black dots in Fig. 8c). For the most part, convective rainfall occurred in places where the $\mathrm{PW}$ was maximal and at locations of higher thermal instability where the PW was still high (Fig. 8c). The ECMWF analysis also indicates more numerous and stronger pockets of positive vertical velocity in the free troposphere together with enhanced low-level convergence in the area (not shown). Nevertheless, vertical velocity is strongly linked to convective processes and displays a very large 

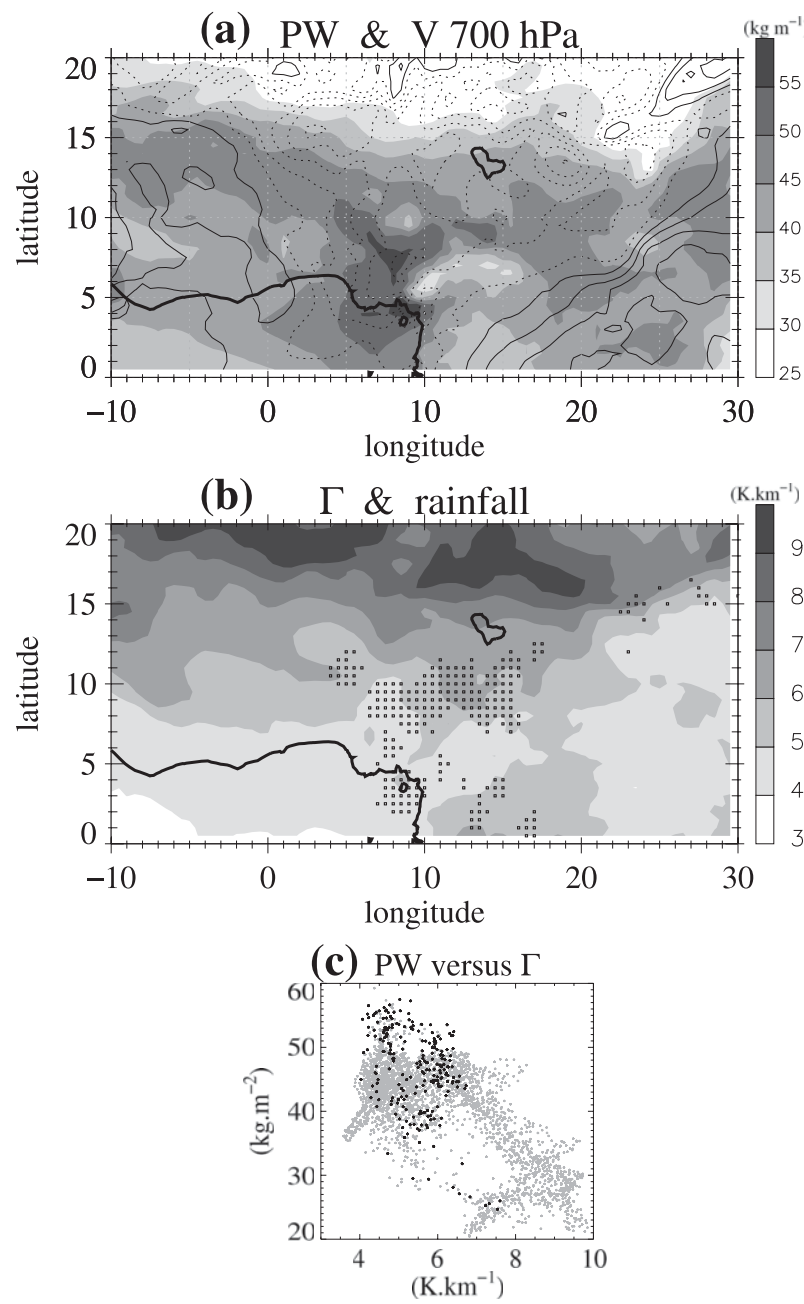

FIG. 8. (a) PW (shading) and meridional wind at $700 \mathrm{hPa}$ from the ECMWF analysis at 0000 UTC 28 Aug 2008. (b) Same as in (a) but for the temperature lapse rate $\Gamma$ between 925 and $700 \mathrm{hPa}$ (shading). Small black squares indicate $0.5^{\circ} \times 0.5^{\circ}$ pixels where rainfall reached more than $25 \mathrm{~mm}$ during the daytime (TRMM3B42RT estimate). (c) Scatter diagram of $\Gamma$ vs PW at 0000 UTC 28 Aug 2008 for the $0.5^{\circ} \times 0.5^{\circ}$ pixels of the area shown in (a). Black dots correspond to the rainy black squares displayed in (b).

variability among the analyses (e.g., Fyfe 1999). Note that high rainfall amounts extend farther westward during the following night as convection is advected by a dominant easterly flow.

On the other hand, the development of convection in mesoscale models typically relies on considerations of instability and/or moisture convergence. Inspection of the results from each mesoscale simulation showed that, indeed, all of the models simulate, as observed, a westward-moving rainfall structure in this area. Differences in their timings are well captured by longitudetime Hovmöller diagrams (Fig. 9, to be compared with
Fig. 5, top). An east-west-moving pattern is simulated, with relatively close speeds among the models.

However, it is not always the dominant pattern. Indeed, rainfall is predicted at night to the east of the rainfall line in most models. The rainfall line itself is less well defined in MesoNH, COSMO, and ECMWF IFS. MesoNH and MOUM are also characterized by widespread daytime convection east of $5^{\circ} \mathrm{E}$. This pattern of behavior may be linked to the closure of their convection schemes, which induces a fast response to the daytime CAPE increase (e.g., Guichard et al. 2004). On the other hand, the differences in the timing of the rainfall cannot be explained simply by considerations of the closures of the different convection schemes (cf. Table 1; e.g., CAPE versus moisture convergence in COSMO). Overall, one may argue that PROMES and WRF provide the best timing. WRF is also the model that allows for a more explicit representation of deep convection. As will be shown in section 7 though, such high resolution is not the only factor required for a better forecast of the timing and location of the rainfall.

Time-latitude diagrams of rainfall point to the difficulty of all of the models in capturing the nighttime northward propagation of rainfall (Fig. 10). Indeed, rainfall either significantly weakens (e.g., in COSMO) and/or is shifted southward; this latter feature is particularly pronounced in ECMWF IFS.

It is not straightforward to assess the simulated rainfall amounts, given the uncertainties affecting the observational products (Fig. 6). The latter suggest that the 24-h rainfall rates are too low in WRF and PROMES, too high in BOLAM and COSMO, and too widespread in MesoNH, ECMWF, and MOUM (Fig. 11).

These results illustrate the current limitations of models in terms of rainfall forecasts over West Africa. Given the actual spreads among the simulations, they cannot be simply and exclusively related to inaccuracies in the representation of MCS motions.

Simulated surface evapotranspiration rates $(E)$ also display distinct ranges and spatial structures (Fig. 12). They are related in various ways to the daytime rainfall field. For instance, in MesoNH, the daytime V-shaped $E$ minimum south of $10^{\circ} \mathrm{N}$ is linked to the occurrence of daytime convection, notably through the associated cloud solar shadowing effect, while the $E$ maxima north of $16^{\circ} \mathrm{N}$ are due to an enhancement of the evaporative fraction and a reduction of the surface outgoing longwave radiation following the rainfall simulated in the early morning, over an area where solar incoming radiation is strong (not shown).

Differences among the simulations are, however, not fully accounted for by such considerations. Differences in the physics are required to explain the distinct 
3-H CUMULATIVE RAINFALL $\left[7^{\circ} \mathrm{N}, 16^{\circ} \mathrm{N}\right]$ AVERAGE
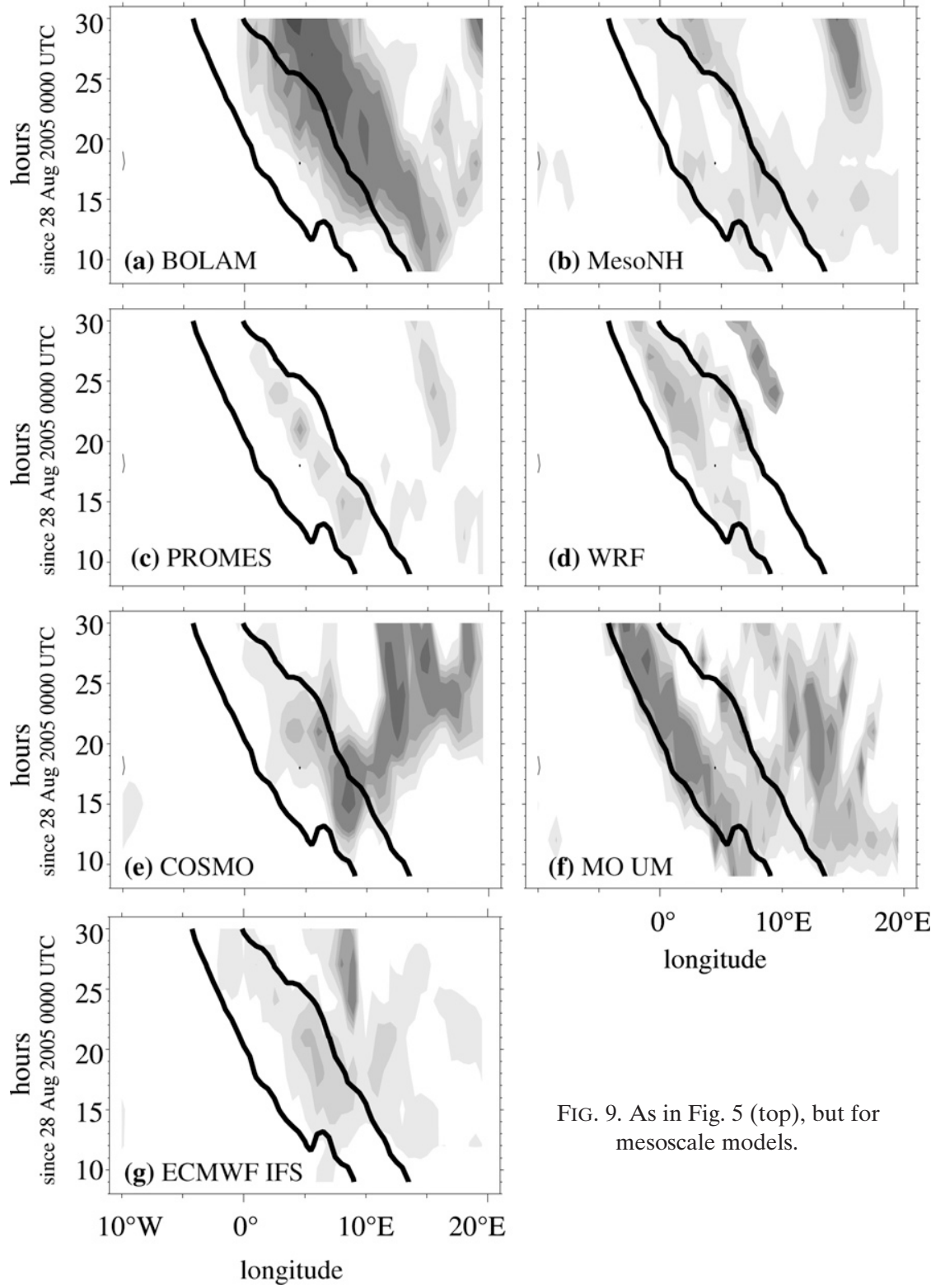

FIG. 9. As in Fig. 5 (top), but for mesoscale models.

magnitudes and latitudinal gradients found among the runs. This involves surface, turbulence, cloud, and convection schemes, but also includes the details of the initialization procedures, for example, of soil moisture. More diagnostics are needed to elucidate this point, as will be addressed in sections 5 and 6 .

The rainiest simulation (BOLAM) has the largest evapotranspiration rate, while the least rainy (PROMES) has the smallest evapotranspiration rate. However, the differences in simulated evapotranspiration alone do not account for the differences in atmospheric water budgets over the $7^{\circ}-16^{\circ} \mathrm{N}, 3^{\circ} \mathrm{W}-10^{\circ} \mathrm{E}$ area. Indeed, the rainfall varies much more across the models than do the evapotranspiration rates. At first order, differences in rainfall account for the very distinct atmospheric circulations and moisture advection indicated by the magnitudes of $P-E$ at this scale (Table 4).

MesoNH and ECMWF IFS provide a coherent zonal band of $E$ maxima (Figs. 12b and 12e), which does not weaken enough to the east nor to the south according to the ALMIP LSM runs (Fig. 7). This latter feature is well captured by PROMES, but the western maximum is not. WRF is relatively close to PROMES apart from the western maximum. However, all the mesoscale models 


\section{3-H CUMULATIVE RAINFALL $\left[5^{\circ} \mathrm{W}, 10^{\circ} \mathrm{E}\right]$ AVERAGE}
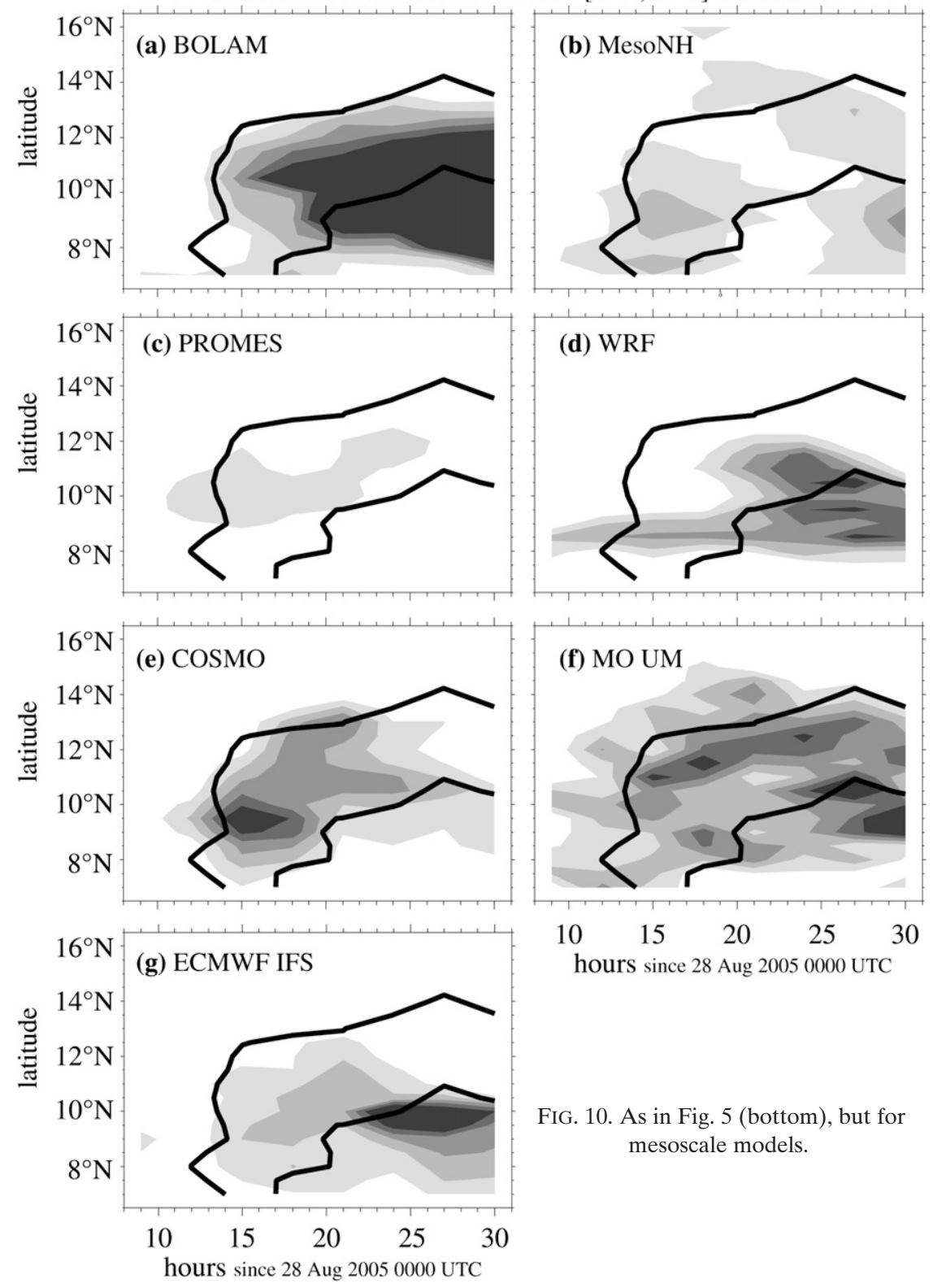

FIG. 10. As in Fig. 5 (bottom), but for mesoscale models.

underestimate the short-term zonal asymmetry indicated by LSMs at the synoptic scale (Fig. 7).

\section{Sources of errors in surface evapotranspiration}

A comparison of Figs. 12b and 7 shows that the simulation of the 24-h mean E by MesoNH is significantly higher than are the values of $E$ provided by all of the LSMs east of $5^{\circ} \mathrm{E}$. A similar conclusion applies to ECMWF-IFS, south of $12^{\circ} \mathrm{N}$. Hereafter, additional results from ISBA, which is the LSM implemented in MesoNH, are used to investigate this issue. First, a comparison of the ISBA and MesoNH surface energy budgets implies that the overestimation of $E$ is not explained in terms of the evaporative fraction (not shown). In fact, prior to any considerations of energy partitioning between the surface sensible and latent heat fluxes, the surface net radiative flux is much larger in MesoNH than in ISBA (Fig. 13). The daily mean differences can locally reach more than $200 \mathrm{~W} \mathrm{~m}^{-2}$, and are approximately $70 \mathrm{~W} \mathrm{~m}^{-2}$ on average over the wide area $5^{\circ}-20^{\circ} \mathrm{N}, 10^{\circ} \mathrm{W}-20^{\circ} \mathrm{E}$. The spatial structures of the differences in Rnet and in surface incoming solar radiation $\left(\mathrm{SW}_{\text {in }}\right)$ closely match each other (Fig. 14). The difference in $\mathrm{SW}_{\text {in }}$ (Fig. 14a) reaches 
(a) BOLAM 24-h cumulative rainfall

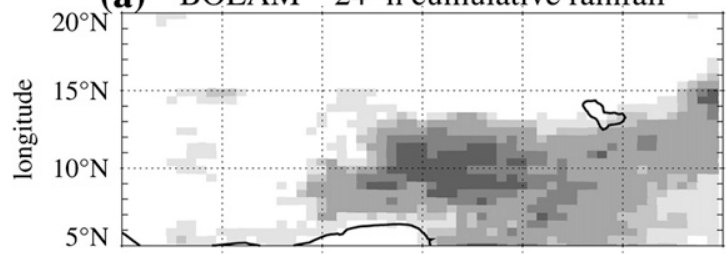

(c) PROMES 24-h cumulative rainfall

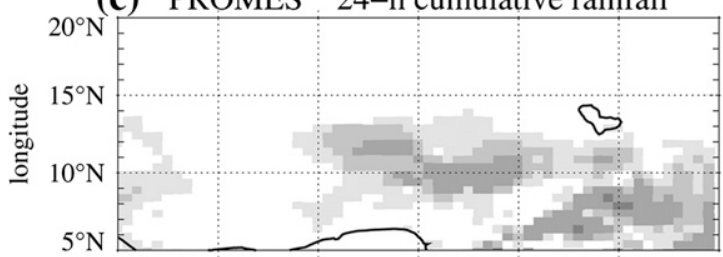

(e)LM-COSMO 24-h cumulative rainfall

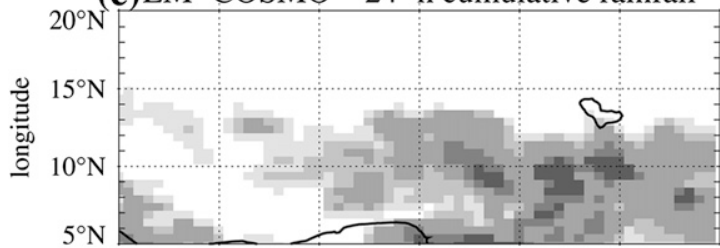

(g)ECMWF IFS 24-h cumulative rainfall

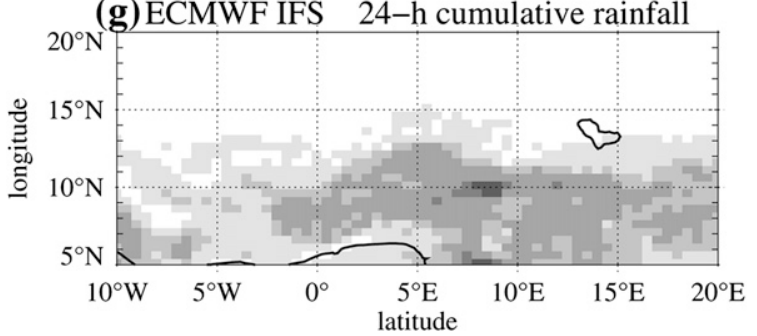

(b) MesoNH 24-h cumulative rainfall

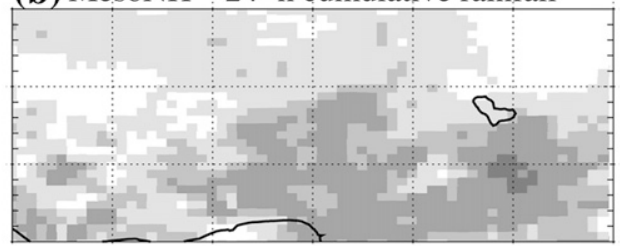

(d) WRF 24-h cumulative rainfall

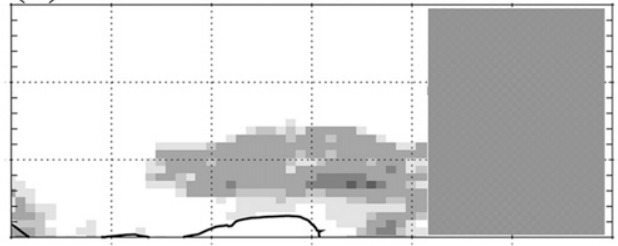

(f) MO UM 24-h cumulative rainfall

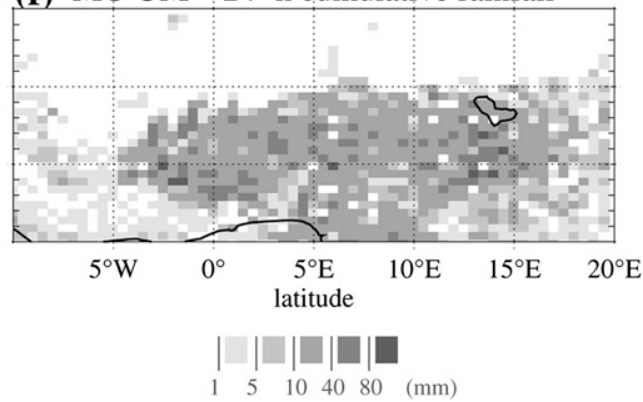

FIG. 11. (a)-(c) As in Figs. 6a-c, but for mesoscale models. (d) For WRF, outputs were not available on the full domain of the simulation (rectangles filled with a hatched pattern).

about $50 \mathrm{~W} \mathrm{~m}^{-2}$, on average, over $24 \mathrm{~h}$ and $5^{\circ}-20^{\circ} \mathrm{N}$, $10^{\circ} \mathrm{W}-20^{\circ} \mathrm{E}$. This corresponds to a relative overestimation of $22 \%$ and points to a lack of cloudiness. These differences are also stronger in the cloudier southern locations. Typically, a "cold start" is used for such modeling; that is, the initial cloud water and/or cloud fraction are set to 0 (a "clear-sky assumption" that is most often not very realistic). Thus, the lack of a cloud initialization method can play a role in this problem, as suggested by a sensitivity test to the date of start. This leads to differences on the order of $30 \mathrm{~W} \mathrm{~m}^{-2}$ for simulations whose starting times were separated by $24 \mathrm{~h}$ (not shown). The particular choice of initial and boundary conditions (i.e., choice of analysis) also affects the cloud field, significantly. Mesoscale simulations using the ARPEGE analysis instead of the ECMWF analysis for the initialization and boundary conditions produce a much cloudier atmosphere $\left(\mathrm{SW}_{\text {in }}\right.$ decreases by about $30 \mathrm{~W} \mathrm{~m}^{-2}$ ). Eventually, some sensitivity to the presence/ absence of a higher-resolution nested domain (simulations HIGHRES and LOW_RES discussed in section 7) was noted, even outside the nested domain, in the form of remote influences over the northern Sahel, and their causes need to be investigated.

The differences in the surface energy budgets are further illustrated by scatterplots of daily values of Rnet versus LE (Fig. 13, bottom). This figure summarizes how higher values of LE in MesoNH are associated with overall higher Rnet than in ISBA, and how the partitioning of the surface fluxes in MesoNH varies mostly with latitude, while ISBA suggests a significant departure from this meridional-mean structure. In addition, the evaporative fraction is overestimated at the northern locations in MesoNH. This feature is at least partly explained by the behavior of the convection scheme: it produces weak but widespread rainfall during daytime, possibly as a result of triggering criteria that are not well suited for this area. 


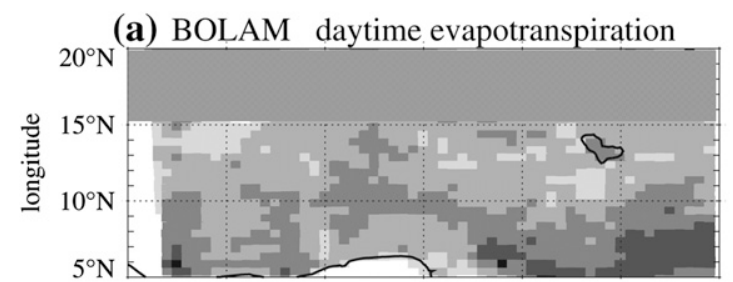

(c) PROMES daytime evapotranspiration

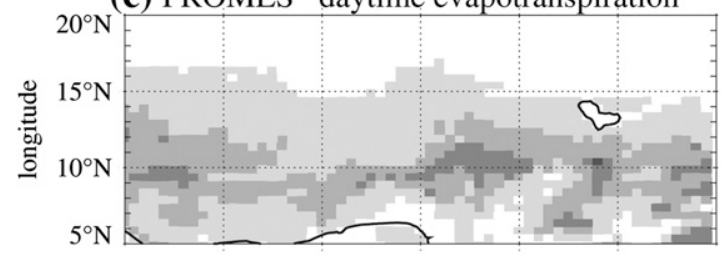

(e) ECMWF IFS daytime evapotranspiration

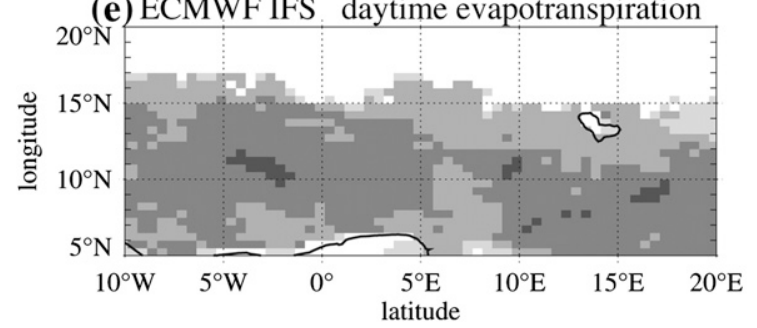

(b) MesoNH daytime evapotranspiration

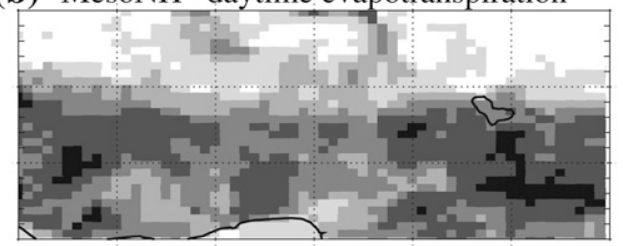

(d) WRF 24-h daytime evapotranspiration

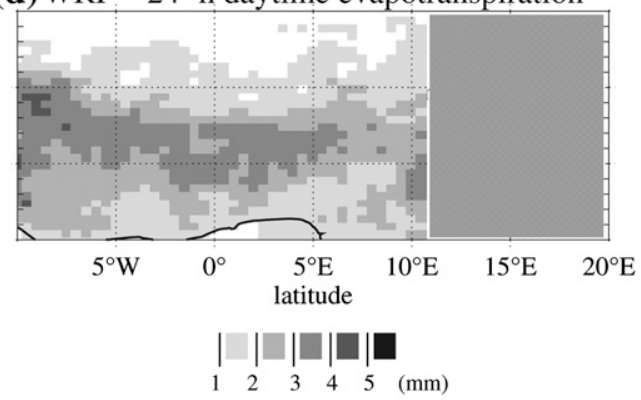

FIG. 12. As in Fig. 7, but for mesoscale models. For (a) BOLAM and (d) WRF, outputs were not available on the full domain of the simulation (rectangles filled with a hatched pattern).

Thus, in addition to inaccuracies arising from a currently too approximate initialization of the surface (not discussed here), the initialization of clouds and the physical parameterizations of the mesoscale models play a significant role in the simulation of the evapotranspiration on short time scales.

\section{Impacts of resolution: Parameterized versus explicit convection}

Rainfall is sensitive to the horizontal resolution of the models, especially when an increase in the horizontal resolution coincides with a change in the treatment of moist precipitating convection, from parameterized (grid mesh larger than about $10 \mathrm{~km}$ ) to explicit (grid mesh lower than about $5 \mathrm{~km}$ ).

This issue is documented below with two simulations. The first one, LOW_RES, uses a uniform $10 \mathrm{~km} \times 10 \mathrm{~km}$ horizontal grid. The second one, HIGHRES, incorporates a nested domain whose horizontal grid is $4 \mathrm{~km} \times 4 \mathrm{~km}$ (Table 2). Both simulations are initialized and forced at their boundaries by the ARPEGE-Tropiques analysis. They forecast close amounts of rainfall, on average, over the inner nested domain (the difference is less than $10 \%$ for the 0600-2400 UTC cumulative rainfall total). However, this results from sharply contrasted space and time distributions of rainfall.

As mentioned above, the convection scheme is responsible for weak but widespread rainfall that starts falling early in LOW_RES and affects most of the domain in LOW_RES. This is still the case in the early afternoon (Fig. 15b). In HIGHRES, the amount of rain is $20 \%$ less for this 3-h period, but it is also much more concentrated in space (Fig. 15f); this pattern results from daytime convection and from a growing MCS centered around $12^{\circ} \mathrm{N}$, $14^{\circ} \mathrm{E}$. Precipitable water displays well-defined patterns

TABLE 4. The 24 -h cumulative rainfall $(P)$ and evapotranspiration $(E)$ over $7^{\circ}-16^{\circ} \mathrm{N}, 3^{\circ} \mathrm{W}-10^{\circ} \mathrm{E}$. Here, $P-E$ provides an estimate of the atmospheric water vapor advection minus the PW tendency.

\begin{tabular}{|c|c|c|c|c|c|c|c|c|c|}
\hline Model & Bolam & MesoNH & PROMES & WRF & COSMO & EPSAT-SG & RFE2 & TRMM & LSM ISBA \\
\hline$P(\mathrm{~mm})$ & 24 & 8 & 3 & 8 & 9 & 11 & 17 & 24 & 11 \\
\hline$E(\mathrm{~mm})$ & 3.5 & 3.5 & 2 & 2.5 & - & - & - & - & 2 \\
\hline$P-E(\mathrm{~mm})$ & 20.5 & 4.5 & 1 & 5.5 & - & - & - & - & 9 \\
\hline
\end{tabular}



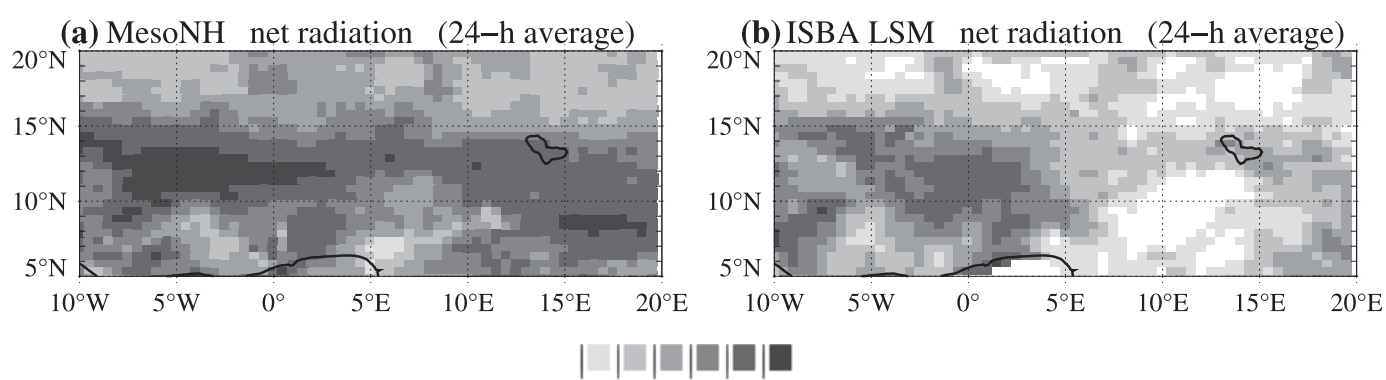

$306090120150180 \quad(\mathrm{~mm})$

(c) MesoNH : Rnet versus LE

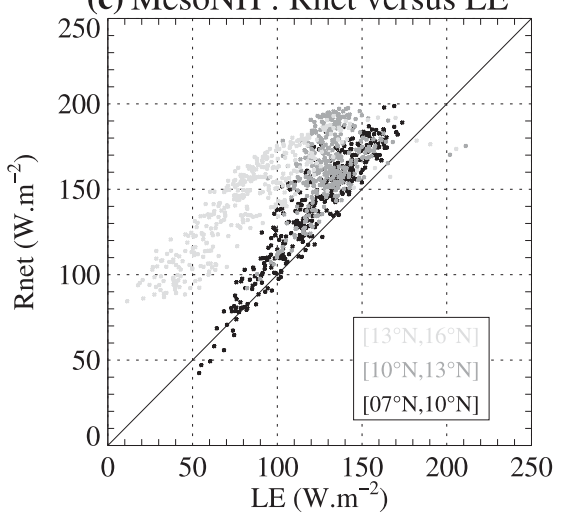

(d) ISBA LSM : Rnet versus LE

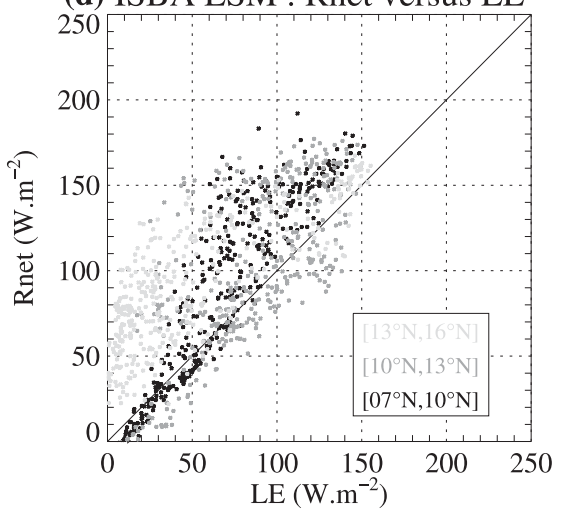

FIG. 13. The 24-h average (top) surface net radiative flux Rnet and (bottom) scatterplots of Rnet vs latent heat flux LE in (left) MesoNH and (right) ISBA. All fields have been interpolated onto the same $0.5^{\circ} \times 5^{\circ}$ grid.

related to these convective phenomena, with a band of maximum PW ahead of the MCS and a significant drying in its wake, and smaller-scale variability farther south (Fig. 15e). In contrast, PW patterns fluctuate less in time in LOW_RES (cf. Figs. 15a and 15c). They are in fact closely linked to the important orographic features of the region, which comprises the Adamawa, Jos Plateau, and Mandara Mountains (PW decreases at higher elevation; see Fig. 15j). The land surface is indeed much flatter farther west. The area north of $10^{\circ} \mathrm{N}$ is drier in the evening (Fig. 15c compared to Fig. 15a), but the drying associated with the passage of the MCS is much stronger in HIGHRES (Figs. 15e and 15g). The imprint of the orography is not absent from HIGHRES but it combines with other significant and rapidly changing factors.

Rainfall starts later, and is also shifted to the north, by a few degrees, in HIGHRES compared to LOW_RES. This is well captured by latitude-time diagrams (Figs. 16a and 16b). The MCS that develops in both simulations moves faster in HIGHRES, although this difference is not so apparent in the rainfall Hovmöller diagrams (Figs. 16c and 16d); the MCS rainfall pattern becomes in fact more dominant later in the night and displays timevarying tilts and several local maxima (not shown). Figure 16c indicates that the band of maximum rainfall is preceded by moistening ahead (thick isolines), and followed by an overall drying in HIGHRES. In LOW_RES,

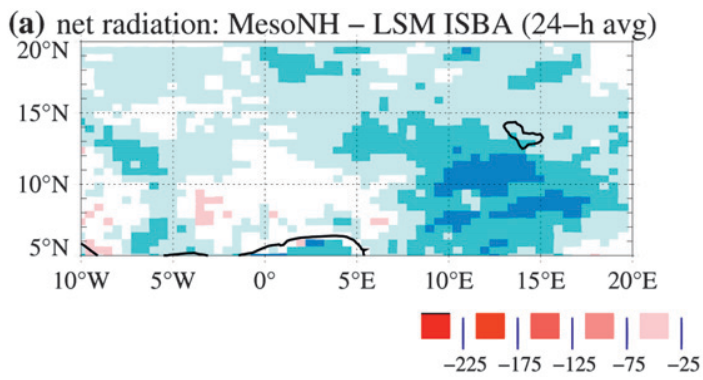

(b) SWin : MesoNH - LSM ISBA (24-h avg)

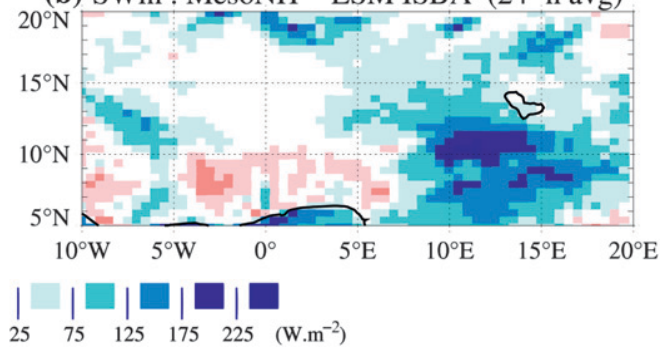

FIG. 14. Differences of (a) surface net radiation between MesoNH and ISBA. (b) As in (a), but for the surface incoming shortwave flux (24-h-average values). All fields have been interpolated onto the same $0.5^{\circ} \times 5^{\circ}$ grid. 
(a) LOW_RES : precipitable water, $15 \mathrm{~h}$

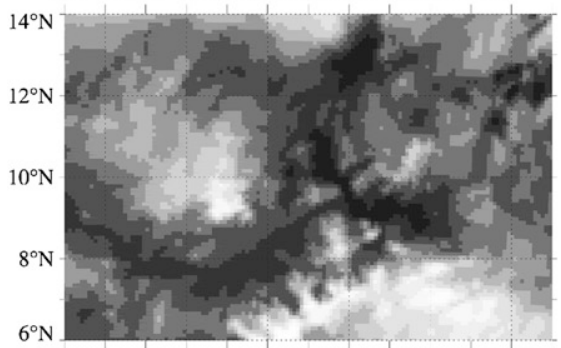

(c) LOW_RES : precipitable water, $20 \mathrm{~h}$

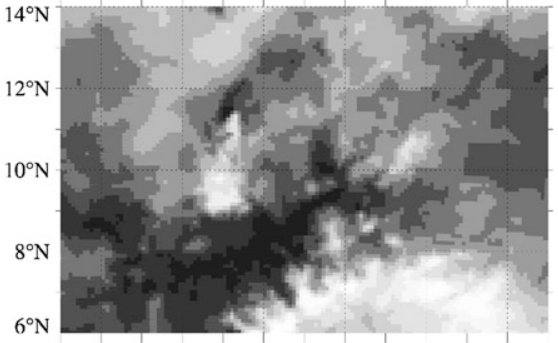

(e) HIGHRES : precipitable water, $15 \mathrm{~h}$

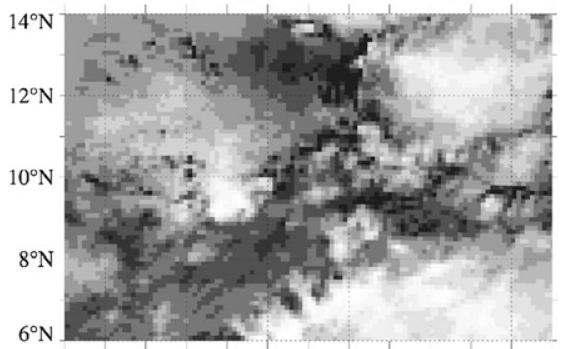

(g) HIGHRES : precipitable water , $20 \mathrm{~h}$

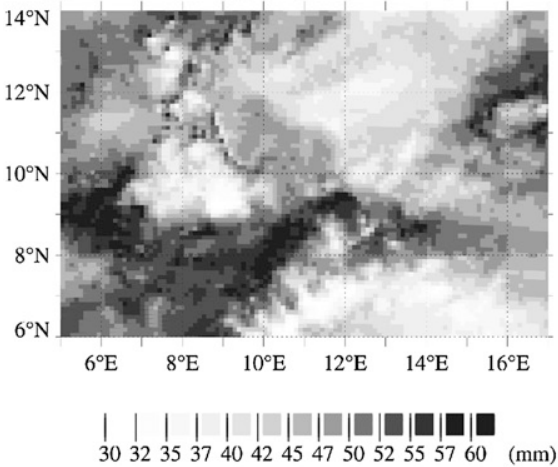

(b) LOW_RES : rainfall $[12 \mathrm{~h}, 15 \mathrm{~h}]$

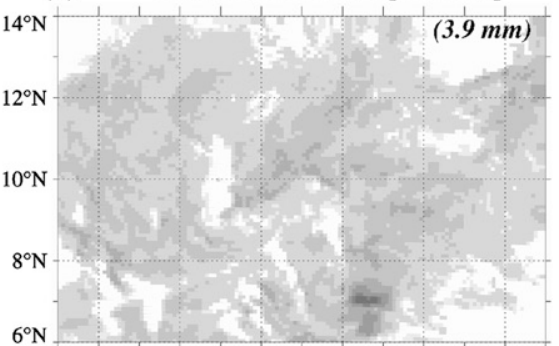

(d) LOW_RES : rainfall [18h,21h]
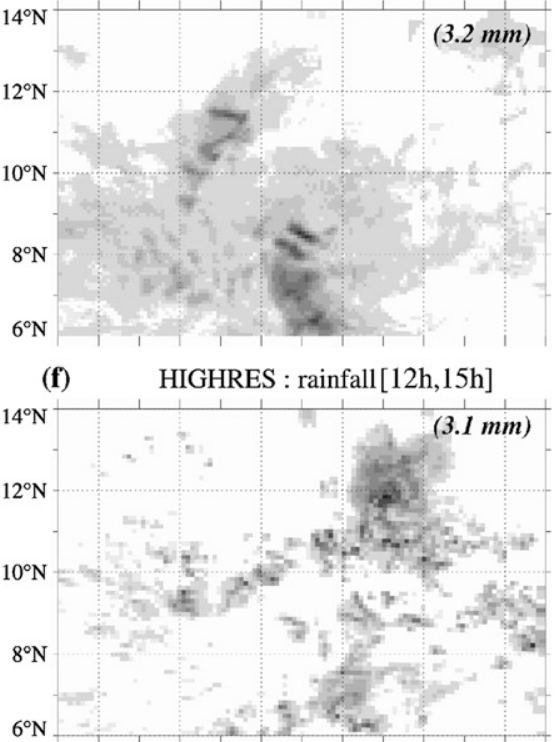

(h) HIGHRES : rainfall $[18 \mathrm{~h}, 21 \mathrm{~h}]$

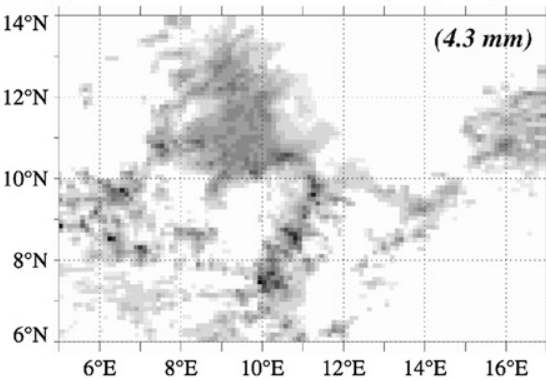

| | | |

$0 \quad 15102030405060708090 \quad(\mathrm{~mm})$

(i) orography

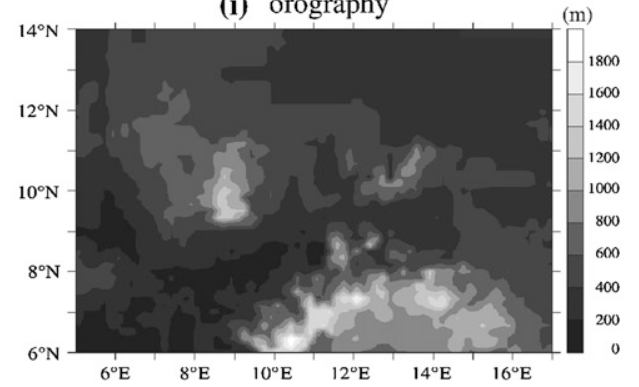

FIG. 15. (left) Instantaneous PW fields and (right) 3-h cumulative rainfall in LOW_RES (top two rows) and HIGHRES (bottom two rows) in the afternoon (first and third rows) and evening (second and fourth rows), and (i) orography. 
RAINFALL (shading) \& PRECIPITABLE WATER (isolines)

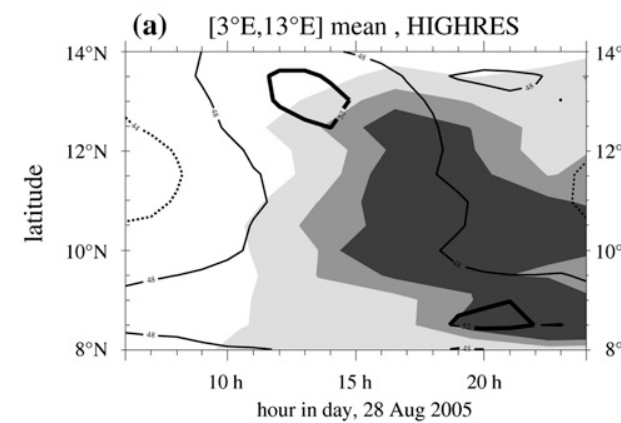

(b) $\left[3^{\circ} \mathrm{E}, 13^{\circ} \mathrm{E}\right]$ mean, LOW_RES
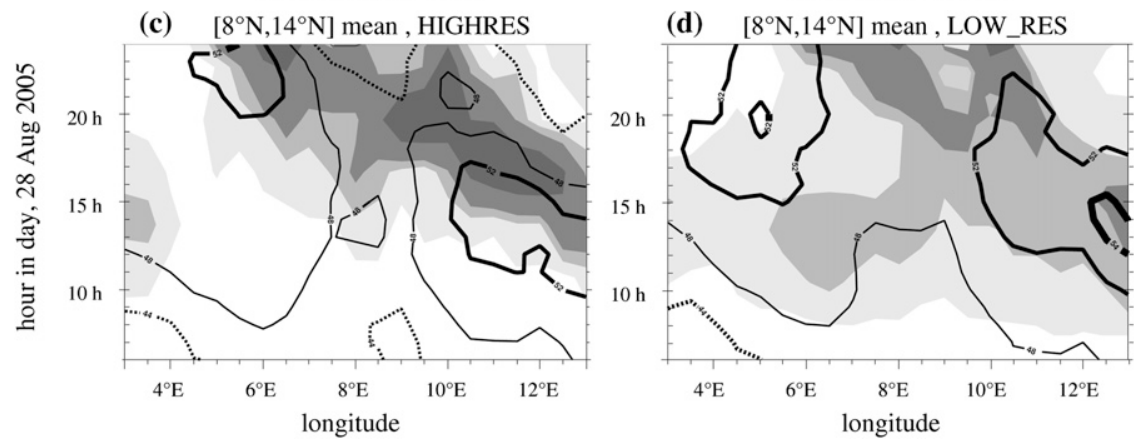

FIG. 16. (top) Latitude-time and (bottom) longitude-time diagrams of 3-h cumulative rainfall (shaded) and 1-h sampled PW, averaged, respectively, over $8^{\circ}-14^{\circ} \mathrm{N}$ and $3^{\circ}-13^{\circ} \mathrm{E}$ in (left) HIGHRES and (right) LOW_RES. Dotted, solid, thick solid, and thickest solid isolines correspond, respectively, to $\mathrm{PW}$ values of $44,48,52$, and $54 \mathrm{~kg} \mathrm{~m}^{-2}$. Lighter to darker shading corresponds to rainfall higher than $1,3,5$, and $10 \mathrm{~mm}$.

PW displays a first daytime maximum east of $10^{\circ} \mathrm{E}$ at around 1400 UTC (Fig. 16d). This PW maximum closely matches the rainfall in Fig. 16d, but is associated with a maximum around $12^{\circ} \mathrm{N}$ (Fig. 16b), which follows the rainfall, instead of the earlier and more northern maximum obtained in HIGHRES (at 1300 UTC; see Fig. 16a). By midnight, the atmosphere has evolved into a moister state in LOW_RES. PW is higher (lower) than at 0600 UTC in LOW_RES (HIGHRES). This occurs despite the cumulative rainfall being $1 \mathrm{~mm}$ higher in LOW_RES compared to HIGHRES.

The early and widespread rainfall simulated in LOW_ RES is associated with stronger evapotranspiration from a wetter surface. In both simulations, $E$ accounts for a significant water vapor input into the atmosphere during daytime, reaching more than $3 \mathrm{~mm}$ at $1600 \mathrm{UTC}$ on average (Fig. 17a). At 1000 UTC, the cumulative evapotranspiration is relatively close in the two simulations, but within $4 \mathrm{~h}$, it becomes about $0.5 \mathrm{~mm}$ higher in LOW_RES. In this case, however, the difference is not directly linked to differences in Rnet: the cumulative Rnet values are close in the simulations and the sensible heat flux is indeed higher in HIGH_RES over the whole latitude band (Fig. 17a, curves on the right). Consistently, scatterplots of $H$ versus LE and Rnet versus LE highlight changes in the partitioning of the surface heat fluxes between LOW_RES and HIGHRES. More energy is converted into sensible heating at the surface, even though the latent heat flux still dominates over most of the area (Fig. 17b). Such a change is large enough to induce an enhancement of the simulated daytime convective boundary layer activity, with higher, warmer, and drier mixed layers in the afternoon, outside of areas perturbed by precipitating convection. As this surface-induced change takes place at a time of the day when the low-level winds are the weakest (e.g., Fig. 1c), its influence on the atmosphere remains more directly linked to the surface below.

Thus, differences in the rainfall, $\mathrm{PW}$, and diurnal cycle point to interactions among processes being more favored at smaller scales, typically on the order of 10 to a few 10s of kilometers, when the representation of moist precipitating processes changes from parameterized (LOW_RES) to explicit (HIGHRES).

\section{Impacts of initial and boundary conditions}

The 24-h maps of rainfall over the whole simulated area illustrate the qualitative agreement of the models at a larger, regional scale, in terms of rainfall occurrence 


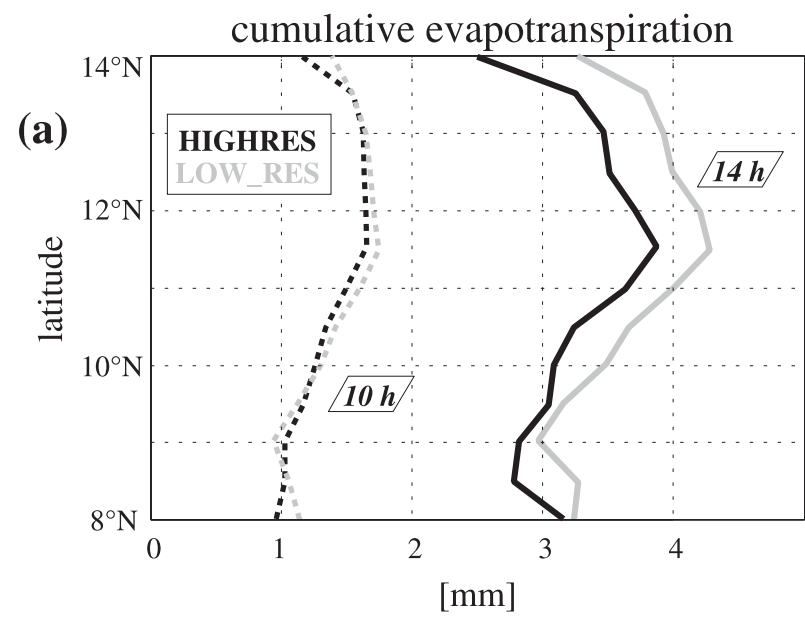

cumul. H / L

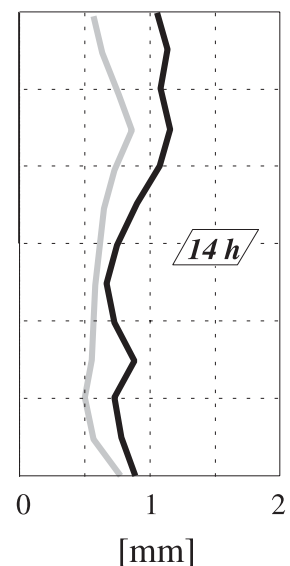

cumul. Rnet / L

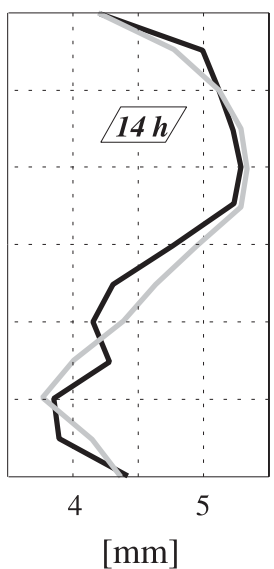

Rnet versus LE

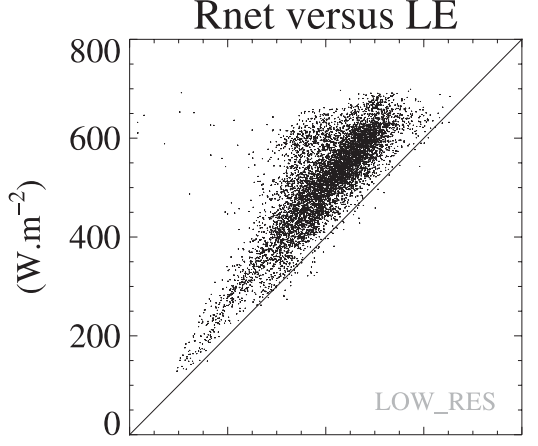

(b)

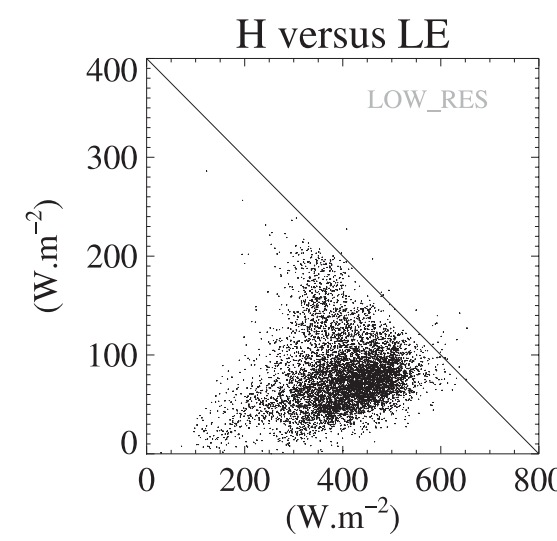

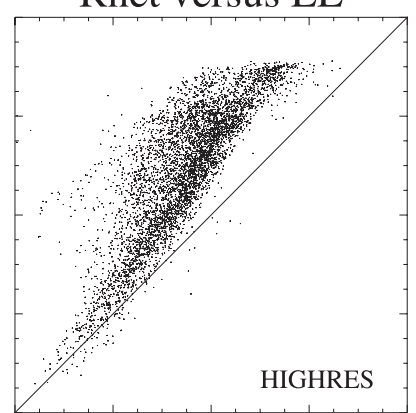

$H$ versus $L E$

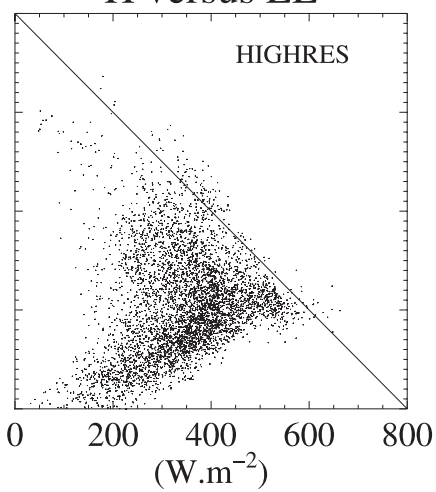

FIG. 17. (top) Cumulative evapotranspiration at 1000 and 1600 UTC, and net radiation divided by the latent heat $L$ at 1400 UTC, averaged over $3^{\circ}-13^{\circ} \mathrm{E}$, and (bottom) Rnet vs LE between 1100 and 1300 UTC (instantaneous values) for LOW_RES (gray lines and dots) and HIGHRES (black lines and dots).

(Fig. 18). As pointed out in section 4, all the mesoscale simulations forecast, as observed, a westward-moving rainfall structure over the area $7^{\circ}-16^{\circ} \mathrm{N}, 3^{\circ} \mathrm{W}-10^{\circ} \mathrm{E}$. All of the models were also initialized and forced at their boundaries by the same NWP analysis.

Sensitivity tests to this factor show that it represents an important aspect of synoptic conditioning. Additional simulations were performed with mesoNH, by alternatively using analyses from the ECMWF and
ARPEGE operational and ARPEGE-Tropiques ${ }^{2}$ forecast systems, referred to respectively as MNHEC,

\footnotetext{
${ }^{2}$ ARPEGE-Tropiques allows the assimilation of more data from the tropics than does the operational ARPEGE NWP system; it is also found to provide better analyses than ARPEGE over West Africa (Nuret et al. 2007). Note that both analyses are much closer to each other than to the ECMWF analysis though. For more information on forecasts over West Africa, see also Lafore et al. (2006).
} 
(a)

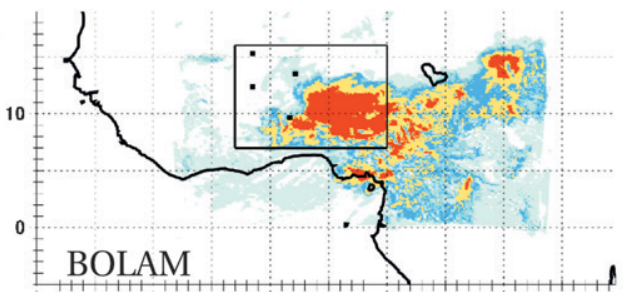

(c)

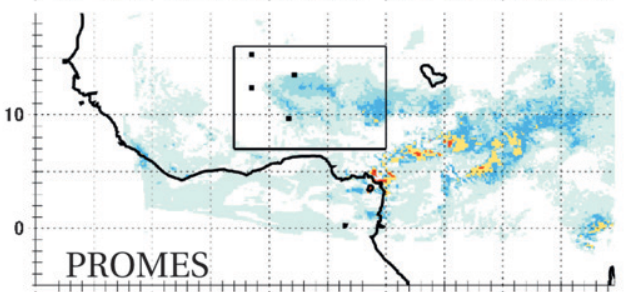

(e)

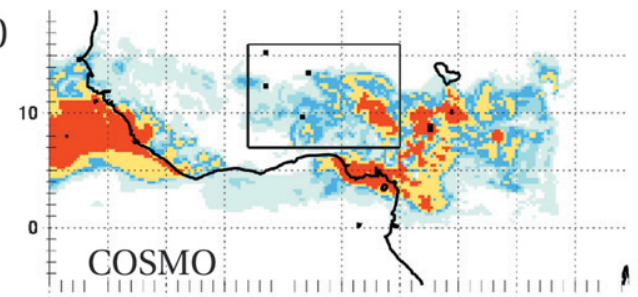

(f)

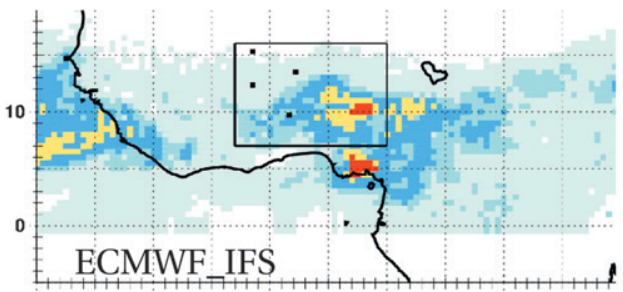

(b)

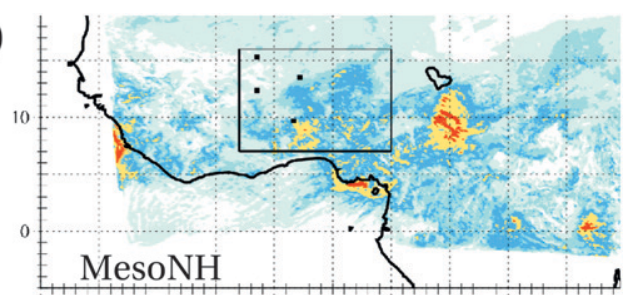

(d)

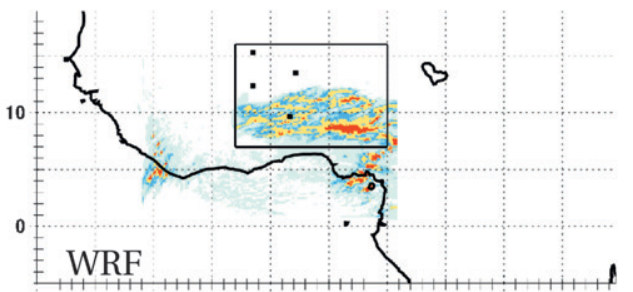

(g)

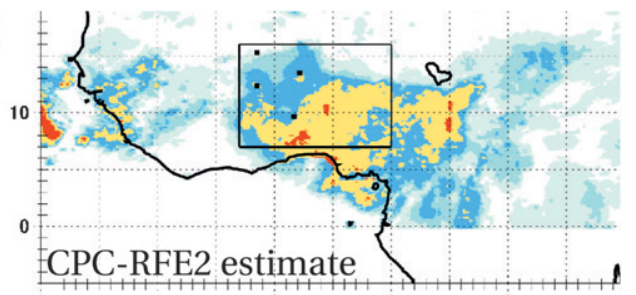

\section{| || || || || || \\ 0.25102050 (mm)}

FIG. 18. The 24-h cumulative rainfall in (a)-(f) mesoscale models over their domains of simulation and (g) the CPC-RFE2 estimate. Note that the full domain in WRF is wider than is shown here (see Table 1) and the MOUM 24-h cumulative rainfall field is computed from 3-h sampled instantaneous values. The time period considered is 0600 UTC 28 Aug-0600 UTC 29 Aug 2005.

MNHAO, and MNHAT (Table 2). A 10-km horizontal grid was employed for these three simulations, which made use of a convective parameterization. The northeast-southwest-elongated rainfall structure forecast by ARPEGE (Fig. 19c) is also simulated in MNHAO (Fig. 19d). It was weaker to the northeast in ARPEGETropiques, and it is also weaker in MNHAT (Figs. 19f and $19 \mathrm{~g}$ ). To the west, and north of $10^{\circ} \mathrm{N}$, the suppressed area is modulated accordingly; that is, it is less pronounced in MNHAO and MNHAT than in MNHEC (Fig. 19b), in the same way as in ARPEGE and ARPEGE-Tropiques compared to the ECMWF forecast (Fig. 19a). This conclusion is supported by visual inspection of the 24-h rainfall fields from simulations performed by the U.K. and NCEP mesoscale models initialized and forced at their boundaries by U.K. UM and NCEP global models. It is also in agreement with results obtained for the other days of the dry-run period (not shown).

The differences between MNHEC and MNHAT can be related to systematic differences in the synoptic environment depicted by the ARPEGE-Tropiques and ECMWF analyses. The amplitude of the meridional wind fluctuations is higher in ARPEGE-Tropiques; PW is also larger (especially to the east in the present case). Overall, these differences in the synoptic structure result in an eastward shift on longitude-time diagrams (Figs. 20a and 20b). Convection developed more eastwardly in MNHAT compared to MNHEC; it was also stronger. Generally, comparisons of ECMWF and ARPEGE-Tropiques (or ARPEGE) indicated a reasonable correspondence of the synoptic dynamical structures, from the height of the 
(a)

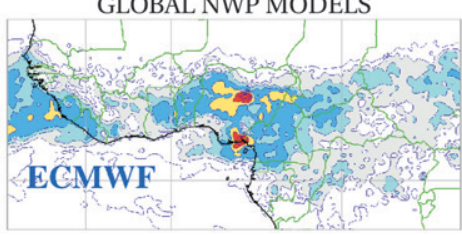

(c)

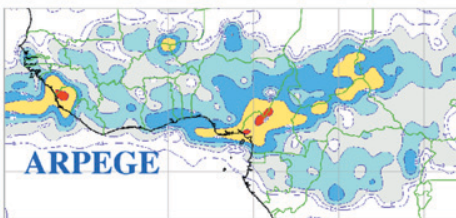

(f)

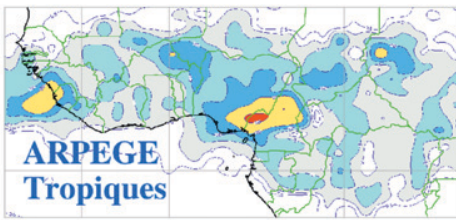

(b)

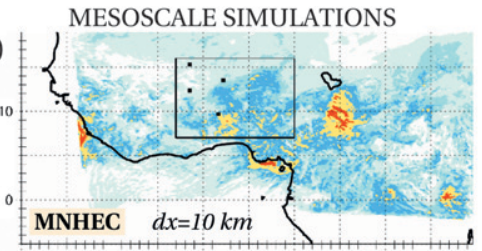

(d)

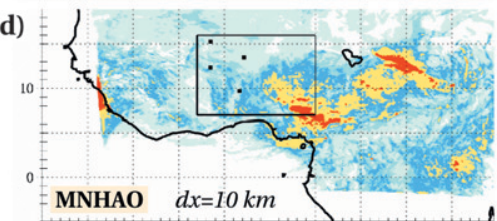

(g)

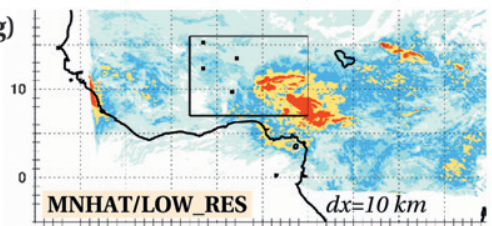

| |1 | || || || || | |

$\begin{array}{llllll}0.2 & 5 & 10 & 20 & 50 & (\mathrm{~mm})\end{array}$

MESO. SIM., ADDITIONAL SENSITIVITIES

(e)

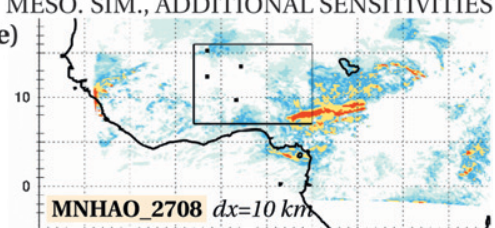

(h)

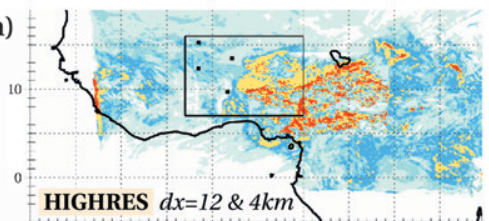

FIG. 19. Same as in Fig. 18 but forecast (left) by the global models ECMWF, ARPEGE, and ARPEGE-Tropiques; (middle) by MesoNH simulations using, respectively, ECMWF, ARPEGE, and ARPEGE-Tropiques analyses for the initial and boundary conditions (MNHEC, MNHAO, and MNHAT). (e) Using ARPEGE analyses but starting 1 day earlier (MNHAO_2708) and (h) using ARPEGETropiques but with high-resolution nested domains (HIGHRES). Figures on the left side have been adapted from original figures available on the 2005 dry-run Web site.

tropical easterly jet (TEJ) around $200 \mathrm{mb}$ to the height of the African easterly jet (AEJ) around 600-700 mb. The differences were more significant in the lower levels, in terms of convective boundary layer height, low-level nocturnal jet height and speed, water vapor, and vertical velocity. Consequently, convective indexes such as CAPE or convective inhibition (CIN) can differ markedly among the two analyses. The analyses of surface properties are also quite distinct. The ARPEGE analysis depicts a moister and more convectively unstable atmosphere. This probably plays a role in the simulation of daytime convection and total rainfall amount. However, the differing locations of the MCS rainfall at synoptic scale often appear to be tied to the initial synoptic structures and vertical velocity fields provided by the analyses.

This synoptic control is relatively short lived however (in agreement with Thorncroft et al. 2003), and the physics of the model can imprint more significantly the rainfall field for longer durations of the simulation. An example is provided by MNHAO_2708; this simulation is similar to MNHAO except that it started $24 \mathrm{~h}$ before (0000 UTC 27 August 2005; see Table 2). The broad northeast-southwest-elongated structure is still forecast in MNHAO_2708 (Fig. 19e to be compared with Fig. 19d). However, the westward extension of rainfall over Nigeria is even more restricted than in MNHAO. In addition, the unrealistic occurrence of widespread weak
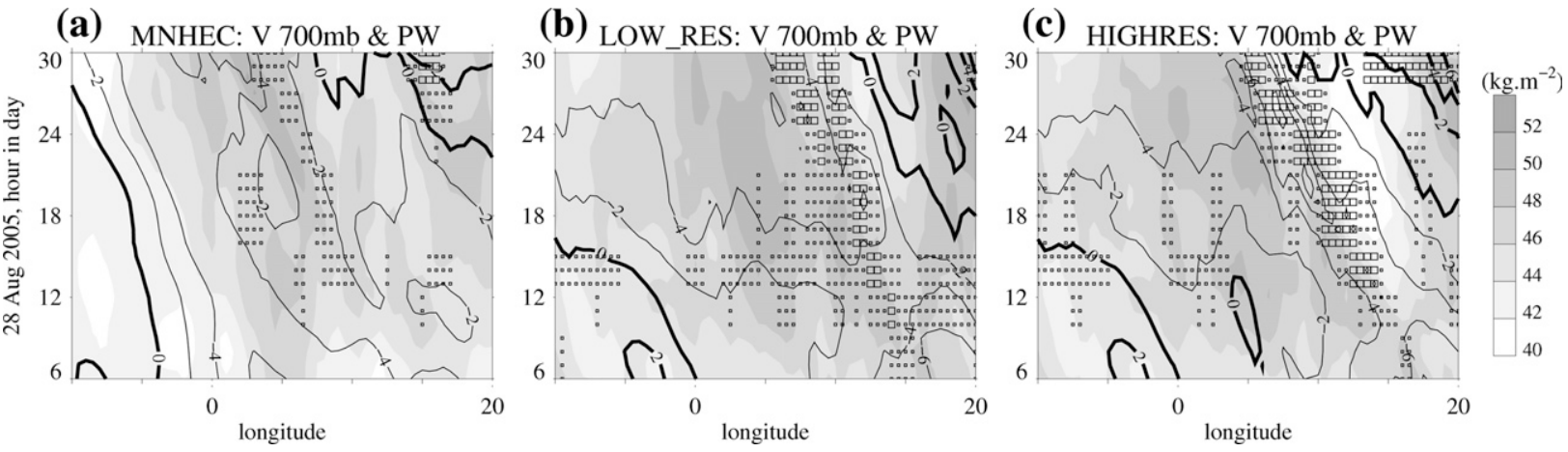

FIG. 20. Longitude-time diagrams of 1 -h meridional wind at $700 \mathrm{hPa}$ (contours, thin lines for negative values) and PW (shading), on average over $7^{\circ}-16^{\circ} \mathrm{N}$ in (a) MNHEC, (b) LOW_RES, and (c) HIGHRES. Smaller and larger black symbols indicate rainfall higher than, respectively, 2 and $5 \mathrm{~mm}$ within $3 \mathrm{~h}$. 
rainfall rates forecast in $\mathrm{MNHAO}$ is significantly reduced in MNHAO_2708. This points to a spindown issue, which is independent of the choice of analysis (MNHAO, MNHAT, and MNHEC similarly forecast unrealistic, widespread weak rainfall), and reflects weaknesses in the physical parameterizations of the model.

Eventually, the use of a finer, $4 \mathrm{~km} \times 4 \mathrm{~km}$, grid on part of the domain, which allows a more explicit representation of moist convection, has a major impact on the rainfall field characteristics. This concerns its western and northern extents, which can be related to the MCS trajectory, but also the spatial scales of the rainfall distribution (Fig. 19h to be compared to Fig. 19g). Eventually at larger scale, it results in much stronger fluctuations of the meridional wind and PW, which propagate westward with time (Figs. 20b and 20c). This reflects major differences in the simulation of the interactions between mesoscale and synoptic-scale processes.

\section{Conclusions and perspectives}

A first evaluation of rainfall and evapotranspiration fields simulated by mesoscale models over West Africa has been performed within AMMA. Six mesoscale models participated in the exercise (BOLAM, MesoNH, PROMES, WRF, COSMO, and MOUM), which focuses on an observed MCS case study. Three-hourly cumulative rainfall and surface evapotranspiration have been intercompared and evaluated with rainfall satellite products and estimates from offline land surface models [as part of ALMIP; Boone et al. (2009)].

Mesoscale simulations initialized and forced at their boundaries by the ECMWF analysis all successfully forecast a westward-moving rainfall structure crossing an area more than $1000 \mathrm{~km}$ wide, as observed by satellite products and simulated by the ECMWF IFS. The simulated timings and speeds of the westward motion of the MCS are often not very accurate, and this is of concern. However, perhaps as important are the facts that (i) for most simulations using a convection scheme significant rainfall amounts are also forecast at locations were it did not rain and (ii) the latitudinal locations of the rainfall vary between models. There is a wide spread in the simulated rainfall rates, but also among the rainfall satellite products. This indicates the need for more accurate rainfall products to properly evaluate the simulated rainfall rates at the mesoscale.

In the varied coupled surface-atmosphere frameworks provided by the six mesoscale models, the simulated $E$ fields exhibited a large spread. They departed significantly from the five, much closer estimates provided by offline LSM runs at synoptic scale. The magnitude of the zonal asymmetry implied by LSMs for this case study is not well simulated, and this appears to be a common weakness of the mesoscale models. However, the differences with the LSMs need to be examined further on an individual model basis. Surface energy budget considerations point to the significance of cloudiness (in addition to surface initialization issues and simulated rainfall) as a source of departure of the mesoscale models from the LSM results. Mean differences with satellite shortwave incoming radiative flux estimates over $24 \mathrm{~h}$ can be as large as $50 \mathrm{~W} \mathrm{~m}^{-2}$ (about 20\%), on average, over areas several hundreds of kilometers wide. It is likely that the "cold start" approach ${ }^{3}$ to model initialization plays a role in this result (Söhne et al. 2008).

More broadly, the initial and boundary conditions appear to significantly control the locations of the simulated rainfall fields at the synoptic scale for 1-2-day forecasts. In this respect, it appears that the selection of the ECMWF analysis for initializing and forcing mesoscale models at their boundaries was a reasonable choice, even though it was dictated by practical considerations. The spatial structures of the initial thermal instability and moisture amount, which are linked to the wave phase, were found to be related to subsequent rainfall. Differences in the precise structures and values of these fields were associated with significant changes in the simulated rainfall field, in terms of location and amount predicted by a given model.

Sensitivity studies suggest that an explicit treatment of moist convection over part of the simulated domain cannot, by itself, correct for weaknesses in an analysis, even though it significantly modifies the rainfall distribution, the trajectory, and the propagation speed of an MCS. Indeed, such simulations are able to represent MCSs over West Africa that share many similarities with observed ones, as shown by Diongue et al. (2002). In the present case, it is also shown that an explicit representation of moist convection favors stronger interactions among surface and atmospheric processes at smaller scales, and is associated with both a drier atmosphere and lower evapotranspiration rates.

The spectacular enhancement of sounding data available in summer 2006 during the largest AMMA field campaign (Parker et al. 2008) made it possible to generate analyses and reanalyses (Agustí-Panareda et al. 2009) of a quality that was probably never achieved in the past. Furthermore, the large amount of data collected during this period (Lebel et al. 2010) ensures the possibility for advanced validations of models. Therefore, the association of high quality analyses, high-resolution mesoscale modeling, and independent data for validation will help

\footnotetext{
${ }^{3}$ That is, an initially cloud-free atmosphere is assumed.
} 
advance our understanding of MCS life cycles over West Africa. This should eventually translate into improvements in the forecasting of rainfall associated with these convective systems.

Acknowledgments. Based on a French initiative, AMMA was built by an international scientific group and is currently funded by a large number of agencies, especially from France, the United Kingdom, the United States, and Africa. AMMA has been the beneficiary of a major financial contribution from the European Community's Sixth Framework Research Programme. Detailed information on the scientific coordination and funding is available online at the AMMA International Web site (http://www.amma-international.org).

The first author thanks F. Favot for her priceless help with data processing, A. Beljaars for his encouragements, and J. Polcher for his comments on an early draft of the manuscript. We warmly thank all our colleagues who participated in the dry-run exercise, and in the realization of the mesoscale and ALMIP runs presented here. Finally, we thank the reviewers for their valuable comments.

Output from the ECMWF-IFS was retrieved from the MARS archive, CPC-RFE2 rainfall estimates were obtained from the Africa data archive at NOAA/CPC, and TRMM rainfall estimates came from the trmmopen ftp site at NASA. We acknowledge the involvement of M. Desbois and colleagues at LMD in the development of EPSAT-SG, as well as exchanges with F. Chopin.

\section{REFERENCES}

Agustí-Panareda, A., and Coauthors, 2009: Radiosonde humidity bias correction over the West African region for the special AMMA reanalysis at ECMWF. Quart. J. Roy. Meteor. Soc., 135, 595-617, doi:10.1002/qj.396.

Arribas, A., C. Gallardo, M. Gaertner, and M. Castro, 2003: Sensitivity of the Iberian Peninsula climate to a land degradation. Climate Dyn., 20, 477-489.

Balsamo, G., P. Viterbo, A. Beljaars, B. van den Hurk, M. Hirsch, A. Betts, and K. Scipal, 2009: A revised hydrology for the ECMWF model: Verification from field site to terrestrial water storage and impact in the Integrated Forecast System. J. Hydrometeor., 10, 623-643.

Bechtold, P., and Coauthors, 2008: Advances in simulating atmospheric variability with the ECMWF model: From synoptic to decadal time-scales. Quart. J. Roy. Meteor. Soc., 134, 1337-1351.

Betts, A. K., and M. J. Miller, 1986: A new convective adjustment scheme. Part II: Single column tests using GATE wave, BOMEX, ATEX and arctic air-mass data sets. Quart. J. Roy. Meteor. Soc., 112, 693-709.

Bock, O., F. Guichard, S. Janicot, J. P. Lafore, M.-N. Bouin, and B. Sultan, 2007: Multiscale analysis of precipitable water vapor over Africa from GPS data and ECMWF analyses. Geophys. Res. Lett., 34, L09705, doi:10.1029/2006GL028039.

Boone, A., and Coauthors, 2009: The AMMA Land Surface Model Intercomparison Project (ALMIP). Bull. Amer. Meteor. Soc., 90, 1865-1880.
Bukovsky, M. S., J. S. Kain, and M. E. Baldwin, 2006: Bowing convective systems in a popular operational model: Are they for real? Wea. Forecasting, 21, 307-324.

Chen, F., and J. Dudhia, 2001: Coupling an advanced land surfacehydrology model with the Penn State-NCAR MM5 modelling system. Part I: Model implementation and sensitivity. Mon. Wea. Rev., 129, 569-585.

Chopin, F., J. C. Bergès, M. Desbois, I. Jobard, and T. Lebel, 2004: Multi-scale precipitation retrieval and validation in African monsoon systems. Extended Abstracts, Second Int. TRMM Science Conf., Nara, Japan, JAXA, 6.8. [Available online at http://www.eorc.jaxa.jp/TRMM/museum/event/2ndTISC/HP/ Extended_Abstract/6.8_DESBOIS_Michel.pdf.]

Corfidi, S. F., 2003: Cold pools and MCS propagation: Forecasting the motion of downwind-developing MCSs. Wea. Forecasting, 18, 997-1017.

Couvreux, F., F. Guichard, O. Bock, B. Campistron, J.-P. Lafore, and J.-L. Redelsperger, 2010: Synoptic variability of the monsoon flux over West Africa prior to the onset. Quart. J. Roy. Meteor. Soc., in press.

Davis, C. A., K. W. Manning, R. E. Carbone, S. B. Trier, and J. D. Tuttle, 2003: Coherence of warm-season continental rainfall in numerical weather prediction models. Mon. Wea. Rev., 131, 2667-2679.

Diongue, A., J.-P. Lafore, and J.-L. Redelsperger, 2002: Numerical study of a synoptic weather system: Initiation and mature stages of convection and its interactions with the large-scale dynamics. Quart. J. Roy. Meteor. Soc., 128, 1899-1927.

Doms, G., and U. Schättler, 2002: A description of the nonhydrostatic regional model LM. Part I: Dynamics and numerics. Consortium for Small-Scale Modelling (COSMO), 134 pp. [Available online at http://www.cosmo-model.org.]

Done, J. M., G. C. Craig, S. L. Gray, P. A. Clark, and M. E. B. Gray, 2006: Mesoscale simulations of organized convection: Importance of convective equilibrium. Quart. J. Roy. Meteor. Soc., 132, 737-756.

d'Orgeval, T., J. Polcher, and P. de Rosnay, 2008: Sensitivity of the West African hydrological cycle in ORCHIDEE to infiltration processes. Hydrol. Earth Syst. Sci. Discuss., 5, 2251-2292.

Doswell, C. A., III, 1987: The distinction between large-scale and mesoscale contributions to severe convection: A case study example. Wea. Forecasting, 2, 3-16.

Drusch, M., and P. Viterbo, 2007: Assimilation of screen-level variables in ECMWF's Integrated Forecast System: A study on the impact on the forecast quality and analyzed soil moisture. Mon. Wea. Rev., 135, 300-314.

Essery, R. L. H., M. Best, R. Betts, P. Cox, and C. M. Taylor, 2003: Explicit representation of subgrid heterogeneity in a GCM land surface scheme. J. Hydrometeor., 4, 530-543.

Fyfe, J. C., 1999: Climate simulations of African easterly waves. J. Climate, 12, 1747-1769.

Gallée, H., and Coauthors, 2004: A high resolution simulation of a West African rainy season using a regional climate model. J. Geophys. Res., 109, D05108, doi:10.1029/2003JD004020.

Gregory, D., and P. R. Rowntree, 1990: A mass-flux convection scheme with representation of cloud ensemble characteristics and stability dependent closure. Mon. Wea. Rev., 118, 1483-1506.

, J. J. Morcrette, C. Jakob, A. C. M. Beljaars, and T. Stockdale, 2000: Revision of convection, radiation and cloud schemes in the ECMWF Integrated Forecasting System. Quart. J. Roy. Meteor. Soc., 126, 1686-1710.

Guichard, F., D. Parsons, and J. Dudhia, 2000: COARE simulations with the mesoscale model MM5: Various sensitivities to 
physical parameterizations. Preprints, 24th Conf. on Hurricanes and Tropical Meteorology, Fort Lauderdale, FL, Amer. Meteor. Soc., 344-345.

— , and Coauthors, 2004: Modelling the diurnal cycle of deep precipitating convection over land with CRMs and SCMs. Quart. J. Roy. Meteor. Soc., 130, 3139-3172.

Hourdin, F., and Coauthors, 2010: AMMA-Model Intercomparison. Bull. Amer. Meteor. Soc., in press.

Houze, R. A., and A. K. Betts, 1981: Convection in GATE. Rev. Geophys. Space Phys., 19, 541-576.

Huffman, G. J., and Coauthors, 2007: The TRMM multisatellite precipitation analysis: Quasi-global, multiyear, combinedsensor precipitation estimates at fine scale. J. Hydrometeor., 8, 38-55.

Janjić, Z. I., 1994: The step-mountain Eta coordinate model: Further developments of the convection closure schemes. Mon. Wea. Rev., 122, 927-945.

Jankov, I., W. A. Gallus Jr., M. Segal, B. Shaw, and S. E. Koch, 2005: The impact of different WRF model physical parameterizations and their interactions on warm season MCS rainfall. Wea. Forecasting, 20, 1048-1060.

Kain, J. S., and J. M. Fritsch, 1990: A one-dimensional entraining/ detraining plume model and its application in convective parameterizations. J. Atmos. Sci., 47, 2784-2802.

Lafore, J.-P., and Coauthors, 1998: The Meso-NH atmospheric simulation system. Part 1: Adiabatic formulation and control simulations. Ann. Geophys., 16, 90-109.

— mer SOP of AMMA: Proposition of a synthetic analysis specific to the West Africa. Second THORPEX Int. Science Symp., Landshut, Germany, WMO/TD 1355 and WWRP/ THORPEX 7, 202-203.

Lagouvardos, K., V. Kotroni, A. Koussis, A. Buzzi, and P. Malguzzi, 2003: The meteorological model BOLAM at the National Observatory of Athens: Assessment of two-year operational use. J. Appl. Meteor., 42, 1667-1678.

Laing, A. G., R. Carbone, V. Levizzani, and J. Tuttle, 2008: The propagation and diurnal cycles of deep convection in northern tropical Africa. Quart. J. Roy. Meteor. Soc., 134, 93-109.

Lamptey, B. L., and Coauthors, 2009: International relations: The UCAR Africa initiative. Bull. Amer. Meteor. Soc., 90, 299-303.

Le Barbé, L., and T. Lebel, 1997: Rainfall climatology during the years 1950-90. J. Hydrol., 189, 43-73.

— - , and D. Tapsoba, 2002: Rainfall variability in West Africa during the years 1950-90. J. Climate, 15, 187-202.

Lebel, T., F. Delclaux, L. Le Barbé, and J. Polcher, 2000: From GCM scales to hydrological scales: Rainfall variability in West Africa. Stochastic Environ. Res. Risk Assess., 14, 275-295.

— , and Coauthors, 2010: The AMMA field campaigns: Multiscale and multidisciplinary observations in the West African region. Quart. J. Roy. Meteor. Soc., in press.

Liu, C.-H., M. W. Moncrieff, and W. W. Grabowski, 2001: Explicit and parameterized realizations of convective cloud systems in TOGA COARE. Mon. Wea. Rev., 129, 1689-1703.

, — - J. D. Tuttle, and R. E. Carbone, 2006: Explicit and parameterized episodes of warm-season precipitation over the continental United States. Adv. Atmos. Sci., 23, 91-105.
Lothon, M., F. Saïd, F. Lohou, and B. Campistron, 2008: Observation of the diurnal cycle in the low troposphere of West Africa. Mon. Wea. Rev., 136, 3477-3500.

Love, T. B., V. Kumar, P. P. Xie, and W. Thiaw, 2004: A 20-year daily Africa precipitation climatology using satellite and gauge data. Preprints, 14th Conf. on Applied Climatology, Seattle, WA, Amer. Meteor. Soc., P5.4. [Available online at http://ams.confex.com/ams/pdfpapers/67484.pdf.]

Mathon, V., H. Laurent, and T. Lebel, 2002: Mesoscale convective system rainfall in the Sahel. J. Appl. Meteor., 41, 1081-1092.

Mohr, K. I., 2004: Interannual, monthly, and regional variability in the wet season of the diurnal cycle of precipitation in subSaharian Africa. J. Climate, 17, 2441-2453.

Moncrieff, M. W., and C. Liu, 2006: Representing convective organization in prediction models by a hybrid strategy. J. Atmos. Sci., 63, 3404-3420.

Noilhan, J., and J.-F. Mahfouf, 1996: The ISBA land surface parameterization scheme. Global Planet. Change, 13, 145-159.

Nuret, M., and Coauthors, 2007: Evaluation of forecasting models for AMMA SOPs: ECWMF and Météo-France models. AMMA-EU Rep. D5.1.c, 25 pp.

Parker, D. J., A. Diongue, R. Ellis, M. Felton, C. M. Taylor, C. Thorncroft, and P. Bessemoulin, 2005: The diurnal cycle of the West African monsoon circulation. Quart. J. Roy. Meteor. Soc., 131, 2839-2860.

— , and Coauthors, 2008: The AMMA radiosonde program and its implications for the future of atmospheric monitoring over Africa. Bull. Amer. Meteor. Soc., 89, 1015-1027.

Peugeot, C., and Coauthors, 2007: Report on 28 August 2005 case study simulations. AMMA-EU Rep. D1.2.2.c, 31 pp.

Peyrillé, P., J.-P. Lafore, and J.-L. Redelsperger, 2007: An idealized two-dimensional framework to study the West African monsoon. Part I: Validation and key controlling factors. J. Atmos. Sci., 64, 2765-2782.

Pope, V. D., M. L. Gallani, P. R. Rowntree, and R. A. Stratton, 2000: The impact of new physical parametrizations in the Hadley Centre climate model: HadAM3. Climate Dyn., 16, 123-146.

Redelsperger, J.-L., A. Diongue, A. Diedhiou, J. P. Ceron, M. Diop, J. F. Gueremy, and J. P. Lafore, 2002: Multi-scale description of a Sahelian synoptic weather system representative of the West African monsoon. Quart. J. Roy. Meteor. Soc., 128, 1229-1257.

C. Thorncroft, A. Diedhiou, T. Lebel, D. J. Parker, and J. Polcher, 2006: African Monsoon Multidisciplinary Analysis (AMMA): An international research project and field campaign. Bull. Amer. Meteor. Soc., 87, 1739-1746.

Skamarock, W. C., J. B. Klemp, J. Dudhia, D. O. Gill, D. M. Barker, W. Wang, and J. G. Powers, 2005: A description of the Advanced Research WRF version 2. NCAR Tech. Note 468+STR, 88 pp.

Söhne, N., J.-P. Chaboureau, and F. Guichard, 2008: Verification of cloud cover forecast with satellite observation over West Africa. Mon. Wea. Rev., 136, 4421-4434.

Thorncroft, C. D., and Coauthors, 2003: The JET2000 project: Aircraft observations of the African easterly jet and African easterly waves. Bull. Amer. Meteor. Soc., 84, 337-351.

Tiedtke, M., 1989: A comprehensive mass flux scheme for cumulus parameterization in large-scale models. Mon. Wea. Rev., 117, 1779-1800. 